\title{
Synthesis of dipentaerythritol from pentaerythritol under acidic conditions
}

Mélissa Landart ${ }^{a}$, Marc Lemaire ${ }^{a, *}$ and Estelle Métay ${ }^{a, *}$

${ }^{a}$ Université de Lyon, Université Claude Bernard Lyon1, CNRS, INSA-Lyon, CPE- Lyon, Institut de Chimie et Biochimie Moléculaires et Supramoléculaires, (ICBMS), UMR 5246, Equipe CAtalyse, SYnthèse et ENvironnement (CASYEN), Bâtiment Lederer, 1 rue Victor Grignard, F69100 Villeurbanne Cedex, France. 
Dipentaerythritol (DPE) has been prepared from a slurry of Pentaerythritol (PE) in sulfolane catalyzed by a low amount of sulfuric acid and was isolated with $16 \%$ yield (72\% GPC purity)

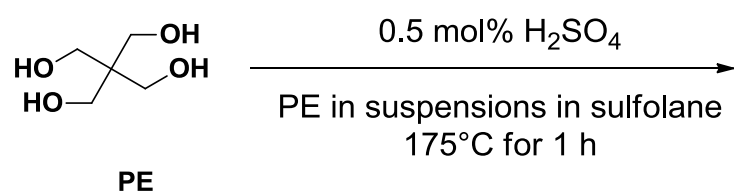

$28 \%$ conversion

and $57 \%$ isolated selectivity.

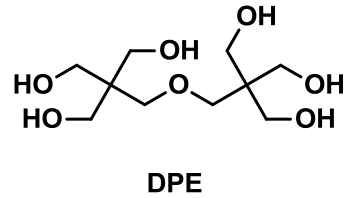

$19 \%$ titrated yield $68 \%$ titrated selectivity

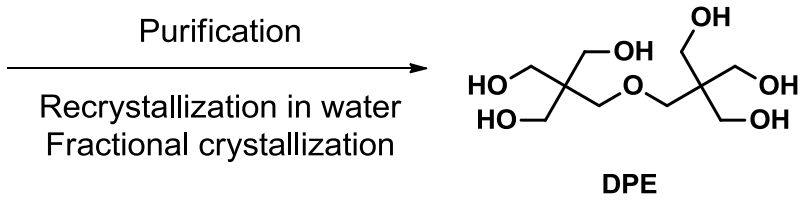

$16 \%$ isolated yield $57 \%$ isolated selectivity 
ABSTRACT: The direct synthesis of dipentaerythritol (DPE) from pentaerythritol (PE) was studied under acidic medium. After optimization of the reaction parameters in batch reactor, DPE was obtained with $50 \%$ selectivity when $50 \%$ of pentaerythritol was converted. This process, using pentaerythritol in suspension in sulfolane (PE/Sulfolane ratio $=2333 \mathrm{~g} / \mathrm{L}$ ) at $175^{\circ} \mathrm{C}$ for $60 \mathrm{~min}$, required a low amount of sulphuric acid $(0.5 \mathrm{~mol} \%)$. The optimized conditions were transposed to 140 grams scale process. Finally, DPE was isolated with $16 \%$ yield (72\% GPC purity) for $28 \%$ conversion of PE that corresponds to $57 \%$ DPE selectivity.

KEYWORDS: Selective dimerization, Pentaerythritol (PE), Dipentaerythritol (DPE), Acid catalysis, Dehydration, Condensation

\section{INTRODUCTION}

Dipentaerythritol (DPE) is an attractive raw material used for the production of polyesters, polyethers, polyurethanes, alkyd resins. DPE is also employed in a wide range synthesis of specialty chemicals such as lubricants, coatings, adhesives, plasticizers and cosmetics. ${ }^{1-5}$ The worldwide market value of DPE experienced a steady growth in the past few years and attained 184.6 million USD in 2018. DPE is expected to undergo a sustained demand until 2028. Nevertheless, to the best of our knowledge, no industrial process is dedicated to the sole production of DPE to date. Commercially available DPE is currently a by-product of pentaerythritol (PE) production from acetaldehyde and formaldehyde in basic medium (scheme 1). ${ }^{6,7}$ In this process, DPE yields were low, only reaching up to $10 \%$. 


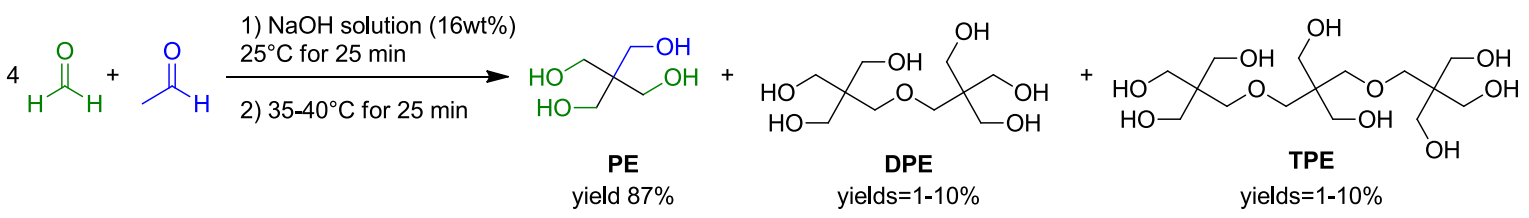

Scheme 1: Synthesis of PE from acetaldehyde and formaldehyde in basic conditions

This lack of efficient process threw up a challenge to develop new methods of DPE synthesis that are economically viable and environmentally friendly. Analysis of the literature revealed that DPE could be prepared from PE under acidic conditions according to three strategies (scheme 2).

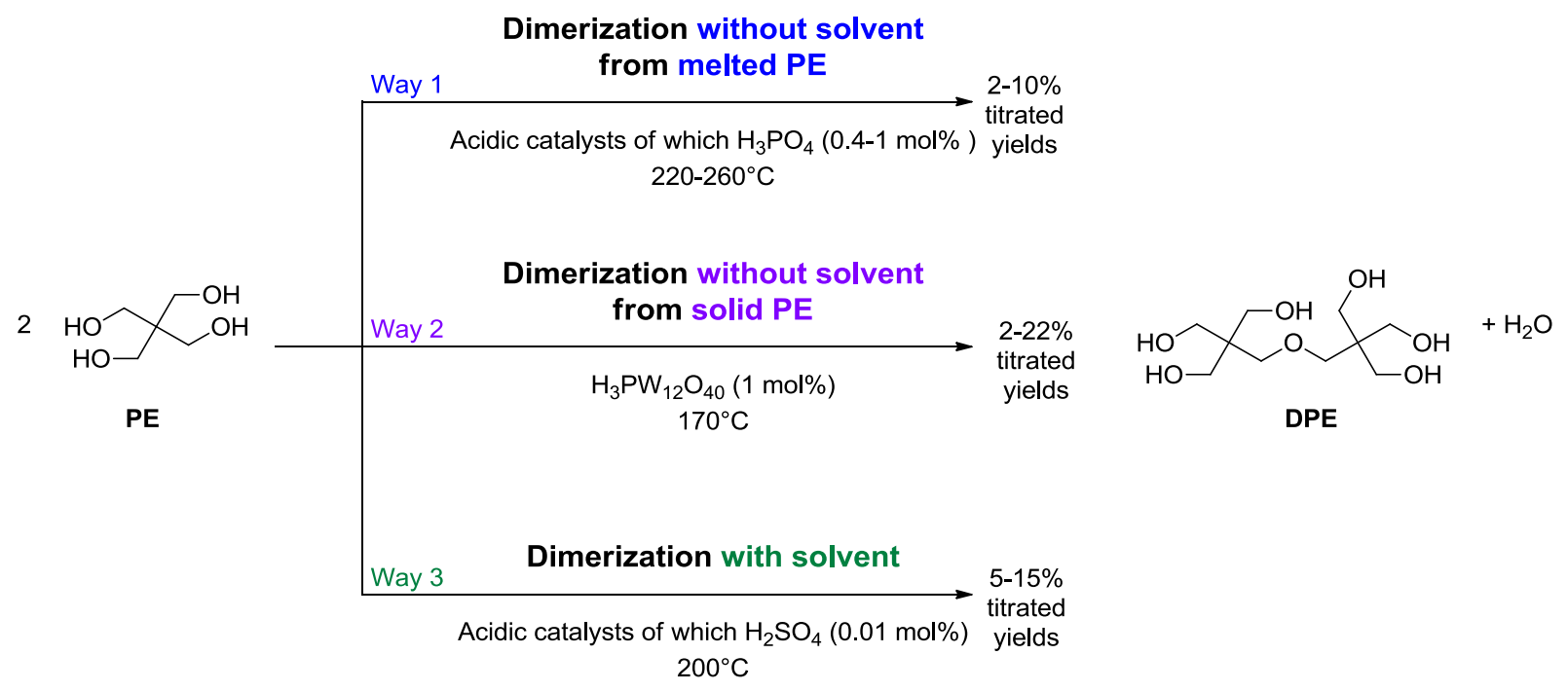

Scheme 2: Direct synthesis of DPE with acid catalysts

In the first strategy, dehydration of $\mathrm{PE}$ is performed from melted $\mathrm{PE} .^{8-11} \mathrm{~A}$ range of inorganic acid catalysts such as phosphoric acid, sulfuric acid, titanium phosphate, zirconium phosphate and $\mathrm{P}_{1} \mathrm{MxSi}_{0-10}$ type catalyst $(\mathrm{x}=\mathrm{V}, \mathrm{Sn}, \mathrm{Ti}, \mathrm{Pb})$ have been reported for the dimerization with melted PE. Synthesis carried out at $240{ }^{\circ} \mathrm{C}$ for $1 \mathrm{~h}$ with phosphoric acid $(0.5 \mathrm{~mol} \%)$ converted from 13 to $16 \%$ of PE whereas DPE was obtained with 9\% DPE titrated yield and thus 55-69\% 
DPE selectivity. ${ }^{8,10}$ In the same way, synthesis performed with zirconium phosphate converted from 14 to $17.6 \%$ of PE and produced $10 \%$ of DPE titrated yield with $56-71 \%$ of DPE selectivity. ${ }^{8,10}$ Nakajima Taro et al. demonstrated that high DPE selectivity (from 68 to $80 \%$ ) could be achieved when PE conversion was very low (from 2 to $8 \%$ ). These results were obtained when the reaction was performed at $260{ }^{\circ} \mathrm{C}$ for 20 min with 3 to $6 \mathrm{wt} \%$ of $\mathrm{P}_{1} \mathrm{MxSi}_{0-10}$ type catalyst $(\mathrm{x}=\mathrm{V}, \mathrm{Sn}, \mathrm{Ti}, \mathrm{Pb}) .{ }^{11}$ Among the processes involving melted $\mathrm{PE}$, the best result concerning DPE selectivity $(80 \%)$ was obtained when a low amount of PE $(3 \%)$ was converted with the use of $\mathrm{P}_{1} \mathrm{~Pb}_{1} \mathrm{Si}_{10}$.

Concerning the second strategy, only one reference in the literature describes the synthesis of DPE from solid PE without solvent. Toshio Okuhara et al. proposed the selective dimerization of the polyol with the use of heteropoly acids such as phosphotungstic acid $\left(\mathrm{H}_{3} \mathrm{PW}_{12} \mathrm{O}_{40}\right)$ and silicasupported 12-tungstosilicic acid $\left(\mathrm{H}_{4} \mathrm{SiW}_{12} \mathrm{O}_{40} / \mathrm{SiO}_{2}\right) .{ }^{12}$ Syntheses performed with those acid catalysts (without solvent) at $170{ }^{\circ} \mathrm{C}$ for $24 \mathrm{~h}$ converted respectively $81.6 \%$ of PE for $22.7 \%$ of DPE titrated yield and $57 \%$ of PE for $22.8 \%$ DPE titrated yield. Among all the acids described in the literature, those heteropoly acid are considered the best catalysts in terms of PE conversion and DPE selectivity.

The third strategy consists in realizing the selective oligomerization of PE in solvents. ${ }^{12-15}$

In this route, $46.5 \%$ of PE was converted giving a $22 \%$ DPE titrated selectivity with the use of water $(\mathrm{PE} /$ water ratio $=4000 \mathrm{~g} / \mathrm{L})$ and phosphoric acid $(0.9 \mathrm{~mol} \%)$. While syntheses performed using sulfuric acid $(0.01 \mathrm{~mol} \%)$ in sulfolane (PE/sulfolane ratio=1260 $\mathrm{g} / \mathrm{L})$ and tridecane $(\mathrm{PE} /$ tridecane ratio=756 g/L) weakly converted $\mathrm{PE}(<30 \%)$ into $43 \%$ and $46 \%$ DPE titrated selectivity. The best DPE titrated selectivity reported in the literature, $77 \%$, was obtained when 
only $13 \%$ of PE was converted in tetralin (PE/tetralin ratio=970 g/L) ${ }^{15}$ Notably, selective dimerization of PE into DPE could be achieved at low conversion of PE (10-30\%).

Due to the few studies reporting the direct dimerization of PE under acidic conditions, analysis of the literature was expanded to other industrially polyols such as trimethylolpropane (TMP), trimethylolethane (TME) and glycerol (GLY). To our knowledge, there also have been very few studies about dimerization of those polyols under acidic conditions (scheme 3).

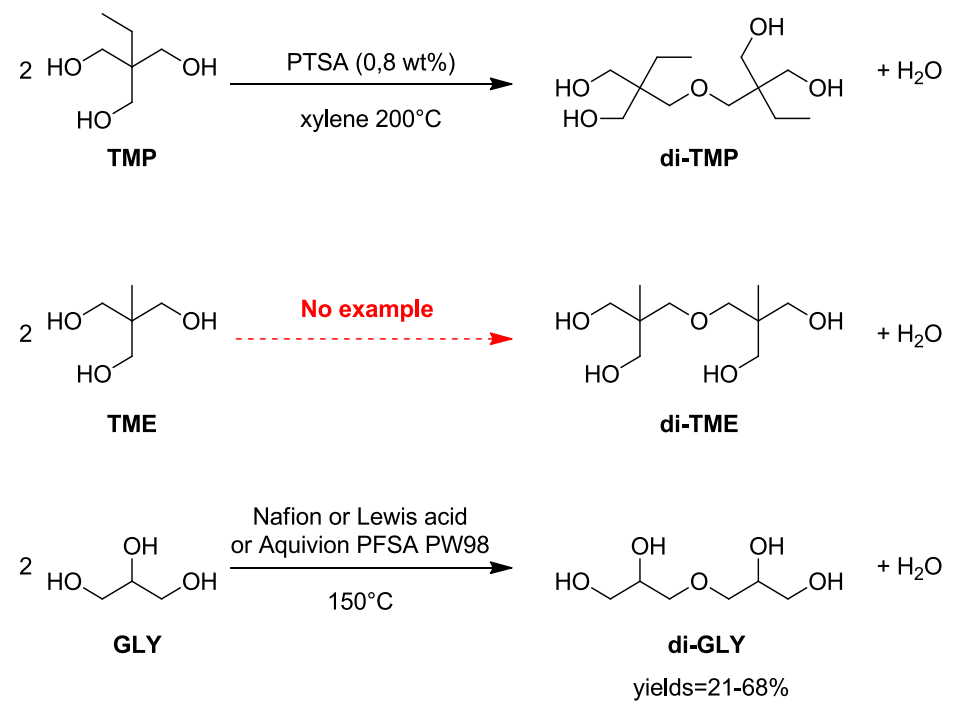

Scheme 3: Dimerization reactions under acidic conditions regarding TMP, TME and GLY

Malec Robert E. proposed a reactive distillation process for the preparation of a mixture containing a substantial amount of ditrimethylolpropane (di-TMP). ${ }^{16}$ The reaction was performed in xylene at $200{ }^{\circ} \mathrm{C}$ with $0.8 \mathrm{wt} \%$ of p-toluene sulfonic acid (PTSA) until $7 \mathrm{wt} \%$ of water was distillated. The exact quantity of synthesized di-TMP was not provided since the reaction medium was directly put in oxidative conditions in order to convert the alcohol functions into acids, which will be then esterified for lubricant applications. 
Manfred Richter et al. proposed to selectively synthesize di-glycerol (di-GLY) from glycerol (GLY) under acidic conditions by the use of a falling film reactor equipped with a roll-like package of Nafion ${ }^{\circledR} .{ }^{17}$ The dimerization was performed at $150{ }^{\circ} \mathrm{C}$ for $12 \mathrm{~h}$ under reduce pressure (4 mbar). The optimized conditions allowed converting 93\% of GLY, giving $68 \%$ di-GLY yield. In addition, François Jérôme et al. described two routes to selectively produce the dimer under acidic conditions. The first one used a Lewis acid, aluminum bis(trifluoromethanesulfonyl)imide $\mathrm{Al}(\mathrm{TFSI})_{3}(1.4 \mathrm{~mol} \%)$, at $150{ }^{\circ} \mathrm{C}$ for $4 \mathrm{~h}$. In these conditions, GLY was converted at $58 \%$ for $31 \%$ di-GLY yield. ${ }^{18}$ The second strategy involved a heterogeneous catalyst, Aquivion $®$ PFSA PW98 (1.4 mol\%), for $6 \mathrm{~h}$ at $150{ }^{\circ} \mathrm{C} .{ }^{19}$ In that way, $82 \%$ of GLY was converted into $21 \%$ diGLY yield. According to the authors, this heterogeneous catalyst could be recycled 10 times without appreciable decrease of activity and selectivity. ${ }^{19}$

Researches developed for the dimerization of GLY into di-GLY could represent a source of inspiration to the selective dimerization of PE into DPE under acidic conditions. However, PE and GLY physico-chemicals properties are totally different which make the syntheses much more difficult to transpose. Indeed, PE is a white crystalline powder, mostly non-soluble in usual organic solvents and melts at $260^{\circ} \mathrm{C}$. Furthermore, another challenge regarding the selective DPE synthesis from PE is suggested by the literature. Competitive oligomerizations of polyols throughout dimerization reaction are promoted under acidic conditions and conduce to molecules of high molecular weight (superior then trimer).

To address these challenges, we performed several attempts without and with solvent. Herein we report the screening of the reaction parameters with solvent. Once the optimized conditions found, DPE selective gram-scale synthesis was achieved. 


\section{RESULTS AND DISCUSSION}

The first studies concerning synthesis of dipentaerythritol (DPE) from pentaerythritol (PE) were performed without additional solvent under acidic conditions. In table 1 are presented the best conditions (temperature, reaction time) for each catalyst. The best conditions, reported in table 1, correspond to the reaction conditions required to obtain the highest DPE selectivity for $50 \%$ minimum PE conversion. The target was fixed to these values for economic reasons and in order to further effectively separate the polyols. Indeed, separation would be more efficient if the reaction medium contains the highest amount of dimer and the lowest amount of PE oligomers (oligo-PE). Those conditions were obtained from optimization studies (available in supporting information) regarding loadings catalysts (trials from 0.25 to $1 \mathrm{~mol} \%$ catalyst), temperature (from 100 to $200^{\circ} \mathrm{C}$ ) and time (from $4 \mathrm{~min}$ to $6 \mathrm{~h}$ ).

Table 1: Outcome regarding direct dimerization of PE under acidic conditions without additional solvent $^{\mathrm{a}}$

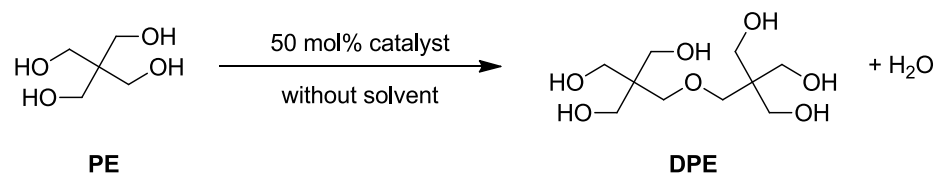

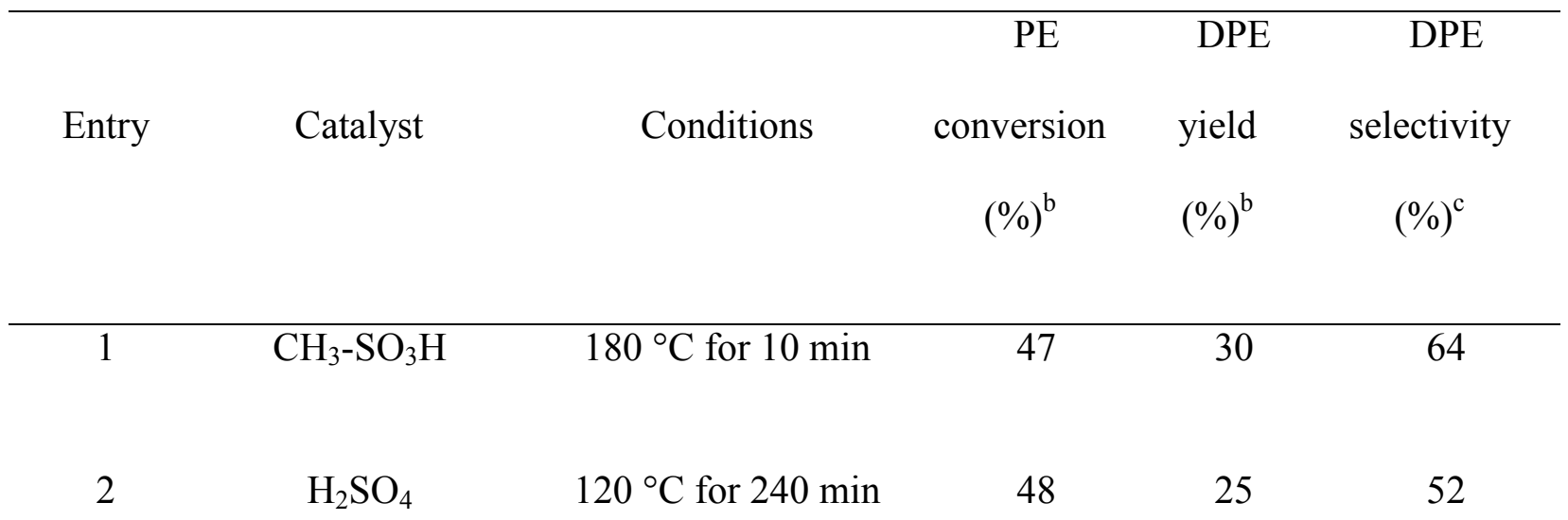


Armstrong's acid

3<smiles>O=C[14c]1ccc2c(S(=O)(=O)O)cccc2c1S(=O)(=O)O</smiles>

$140{ }^{\circ} \mathrm{C}$ for $30 \mathrm{~min}$

$120{ }^{\circ} \mathrm{C}$ for $120 \mathrm{~min}$
50

47
27

54

4
$\mathrm{CF}_{3}-\mathrm{SO}_{3} \mathrm{H}$ $140^{\circ} \mathrm{C}$ or $30 \mathrm{~min}$

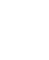

7

7

(2)

${ }^{a}$ Reaction conditions: Sealed tube $(15 \mathrm{~mL})$, PE (7.34 mmol, $\left.1 \mathrm{~g}\right)$, catalyst $(50 \mathrm{~mol} \%){ }^{\mathrm{b}}$ Determined by GPC following the method detailed in supporting information. ${ }^{\mathrm{c}}$ DPE selectivity is calculated from $\left(\frac{\text { DPE yield }}{P E \text { conversion }}\right) \times 100$.

Synthesis performed with methanesulfonic acid at $180{ }^{\circ} \mathrm{C}$ for $10 \mathrm{~min}$ converted $47 \%$ of $\mathrm{PE}$ for $64 \%$ DPE selectivity (table 1, entry 1). In milder conditions, at $120{ }^{\circ} \mathrm{C}$ for 240 min using sulphuric acid and $140{ }^{\circ} \mathrm{C}$ for 30 min catalysed by Armstrong's acid (naphthalene-1,5-disulfonic acid), PE was half converted for 52 and 54\% DPE selectivity (table 1, entries 2 and 3). The best DPE selectivity, $77 \%$, was obtained when $47 \%$ of PE was converted at $120{ }^{\circ} \mathrm{C}$ for 120 min in triflic acid (table 1, entry 4). This overview of the reaction conditions that furnished the bests results regarding DPE selectivity when $50 \%$ of PE was converted come from a screening of conditions available in supporting information.

Nevertheless, solvent-free direct dimerization of PE in acid conditions was not pursued. Indeed reproducibility issues were encountered because of physic aspect of the reaction medium. Systems without solvent were usually very viscous and difficult to stir.

However, the first experimentation highlighted factors which could limit both PE conversion and DPE production during the synthesis. The first one was related to the physicochemical properties of polyols. PE has a higher melting point $\left(260{ }^{\circ} \mathrm{C}\right)$ than DPE $\left(220^{\circ} \mathrm{C}\right)$. This parameter has directly an impact on the heating demand for solvent-free dimerization from melted PE. As 
previously observed, the process implementation of solvent-free dimerization could be complicated through physic aspect of the system (viscosity).

The second factor was DPE reactivity throughout the synthesis. In order to get a better understanding of this reactivity over time, the solvent-free dimerization was studied at $120{ }^{\circ} \mathrm{C}$, using $50 \mathrm{~mol} \%$ of sulphuric acid (figure 1). Taking samples in the same reaction medium over time was difficult due to the viscosity and fast solidification of the system. Consequently, we carried out separate experiments and stopped at different times.

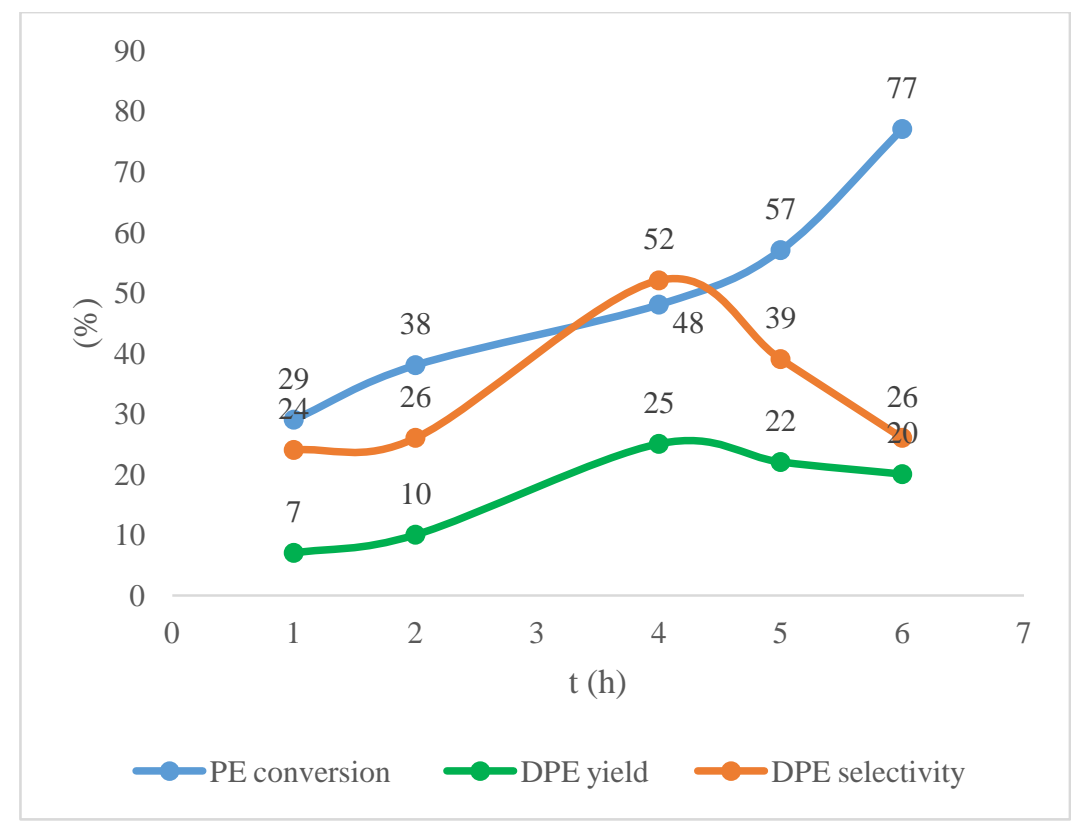

Figure 1: PE conversion and DPE selectivity over time. Reaction conditions: Sealed tube, PE (7.34 mmol, $1 \mathrm{~g}$ ), without solvent, $\mathrm{H}_{2} \mathrm{SO}_{4}(50 \mathrm{~mol} \%), 120{ }^{\circ} \mathrm{C}$. The conversion of $\mathrm{PE}$ and yield of DPE were determined by CPG following the method detailed in supporting information.

In those conditions of reaction, from 1 to $4 \mathrm{~h}$, both PE conversion and DPE selectivity increased respectively from 29 to $48 \%$ and from 24 to $52 \%$. After 4 h, once $50 \%$ of PE was converted, DPE selectivity fell down from $52 \%$ to $26 \%$. This study shown also that even at low PE 
conversion, DPE selectivity was not total and side-reactions occurred since the beginning of the synthesis and among the major side products, TPE was detected (in GPC).

Following observations and comments, we propose a reaction mechanism in order to explain the evolution of DPE yield and selectivity (figure 2).

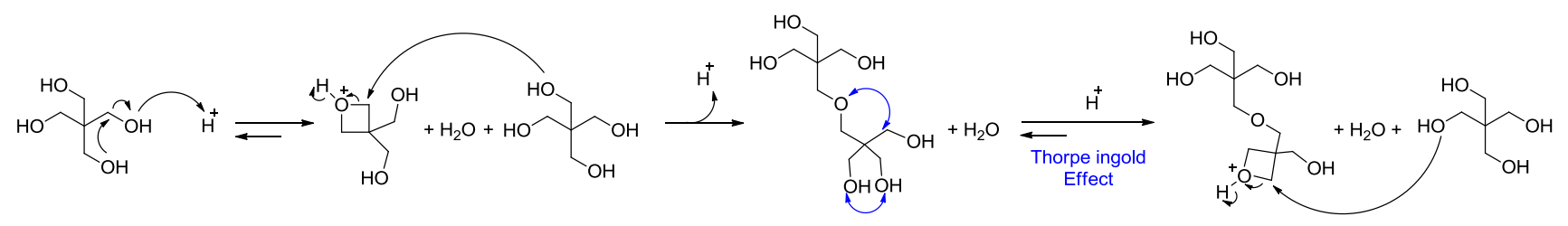

(1)

(2)

(3)

(4)

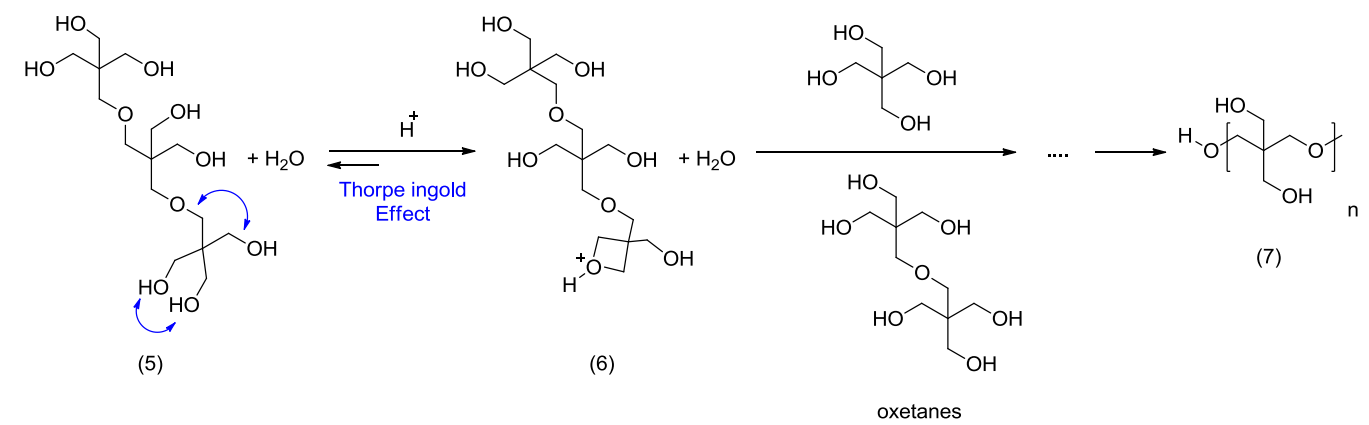

Figure 2: Proposed mechanism for DPE synthesis under acidic conditions

Under acidic conditions, PE (1) could be dehydrated into 3,3-bis(hydroxymethyl)oxetan-1-ium (2) named oxonium-oxetane-PE. Compound (2) was observed in our reaction media and prepared separately to confirm our observations. This species is highly reactive due to the protonation of the oxygen within the cycle and due to its cycle tension. ${ }^{20}$ BHMO oxonium oxetane (2) could rapidly react either with PE (1) in order to form DPE (3), or with DPE (previously produced) to be transformed into TPE (5). It could also react, with another equivalent of (2) thereby resulting in the formation of oligomers (7). Indeed, polymerization of oxetanes in acid conditions is thoroughly reported in the literature. ${ }^{20-22}$ Experimentally, we observed that in 
acidic aqueous conditions, oxetane (2) and (4) can also give PE and DPE. Once DPE (3) is produced, it could also be dehydrated into its oxonium oxetane derivative (4). This oxetane could react with PE (1) to produce TPE (5), or with itself or with BHMO oxonium oxetane (2) resulting in the formation of oligomers (7). TPE (5) could also be transformed into its corresponding oxonium oxetane (6).

Assumptions are that formation of oxetane-TPE (6) should be faster than the formation of oxetane-DPE (4), which should itself be faster than the formation of oxetane-PE (2), due to Thorpe Ingold effect. These hypotheses could explain the facts observed for all the syntheses performed. Even at very low conversion of PE, selectivity of DPE was low. These side reactions appearing from the beginning of the reaction essentially lead to the high reactivity of the oxonium-oxetane-PE (2) and then due to rapid formation of oxonium-oxetane of DPE (4) and TPE (6). It appeared that a maximum was reached when $50 \%$ of PE was converted with a maximum of $50 \%$ DPE selectivity. Beyond this point, DPE selectivity rapidly decreased. This could be explained by the fact that at this maximum, the reaction medium is composed of a mix of polyols and oxonium-oxetanes species which rapidly react with each other in order to form molecules with higher molecular weight than the trimer (7). The main challenge of DPE selectivity improvement is essentially due to the formation of those oxetanes throughout the DPE synthesis in acid conditions.

In order to optimize this process, it was necessary to consider both chemical and physical aspects of the polyols. Performing the selective dimerization in solvent could require less heating and solved reproducibility issues encountered in free-solvent dimerization. Thus, several experiments were undertaken to identify a solvent for the production of DPE from PE. These polyols were 
insoluble in acetonitrile, ethyl acetate, acetone, diethyl ether, PEG 200, cyclopentyl methyl ether (CPME); 2-methylbutan-2-ol, N-methyl-2-pyrrolidone (NMP), 1,3-dimethyl-2-imidazolidinone (DMI), dichloromethane, chloroform, cyclohexane. Solubility differences between PE and DPE was observed in several polar solvents (table 2).

Table 2: PE solubility and DPE solubility in usual solvents
Solvent
$\mathrm{T}\left({ }^{\circ} \mathrm{C}\right)$
PE solubility
DPE solubility

$\begin{array}{lccc}\text { Trimethylolpropane } & 100 & \text { Very slightly soluble } & \text { Insoluble } \\ \text { Sulfolane } & 100 & \text { Soluble } & \text { Very slightly soluble } \\ \text { DMSO } & 100 & \text { Soluble } & \text { Soluble } \\ \text { Water } & 100 & \text { Soluble } & \text { Very slightly soluble } \\ \text { Methanol } & 65 & \text { Very slightly soluble } & \text { Insoluble } \\ \text { Ethanol } & 78 & \text { Very slightly soluble } & \text { Insoluble } \\ \text { Acetic acid } & 100 & \text { Very slightly soluble } & \text { Insoluble }\end{array}$

PE and DPE are insoluble in most of solvents excepted in water, sulfolane and DMSO. Additional solubility tests were performed in order to determine more precisely solubility limits of the polyols in those solvents (figures 3 and 4). 


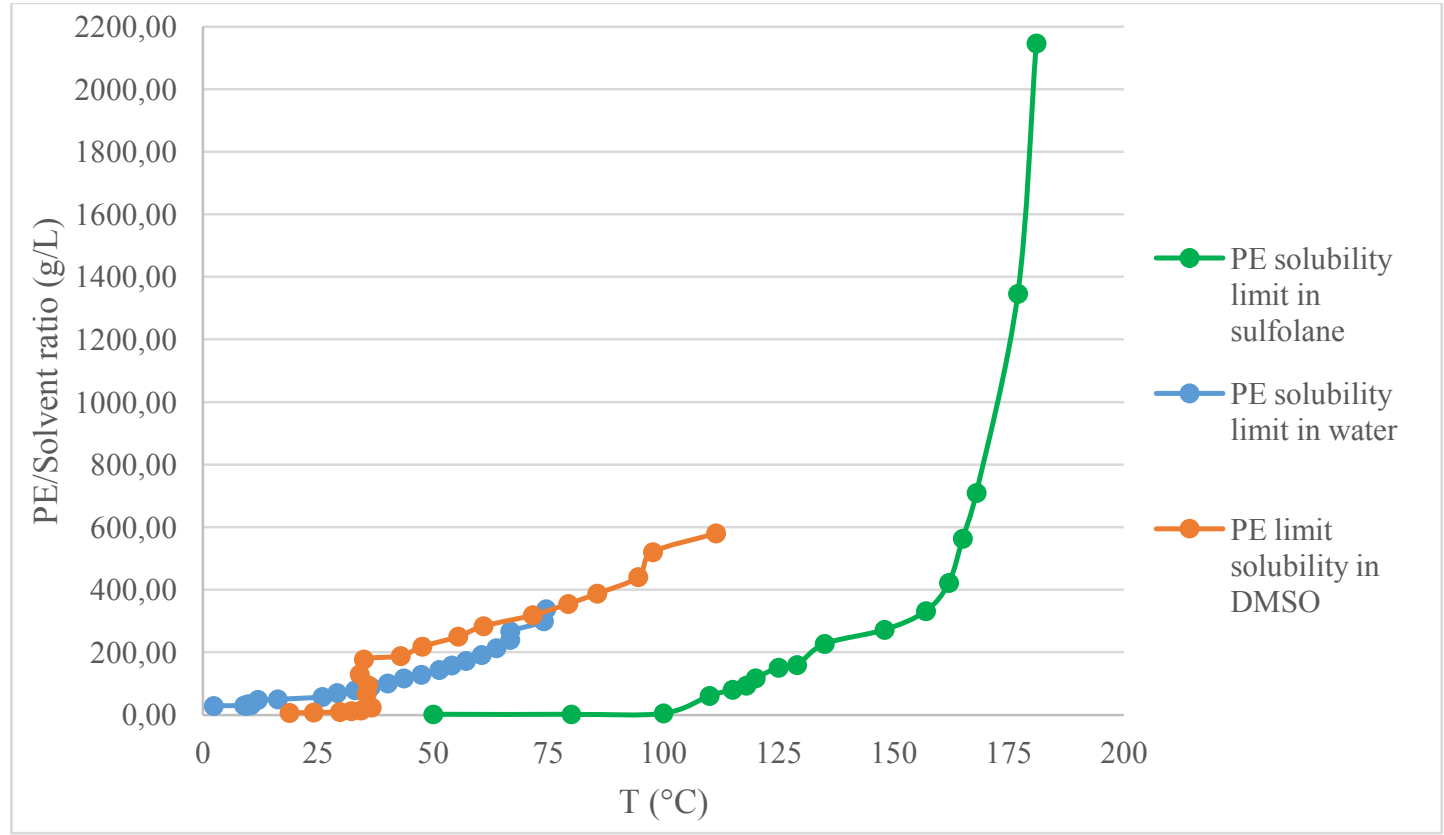

Figure 3: Limit solubility of PE in sulfolane, water and DMSO.

PE presents a relatively good solubility in water $\left(46 \mathrm{~g} / \mathrm{L}\right.$ at $20^{\circ} \mathrm{C}$, blue curve on figure 3$)$, in dimethyl sulfoxide (DMSO; $44 \mathrm{~g} / \mathrm{L}$ at $36{ }^{\circ} \mathrm{C}$, orange curve on figure 3$)$ and in sulfolane $(37 \mathrm{~g} / \mathrm{L}$ at $110^{\circ} \mathrm{C}$, green curve on figure 3 ).

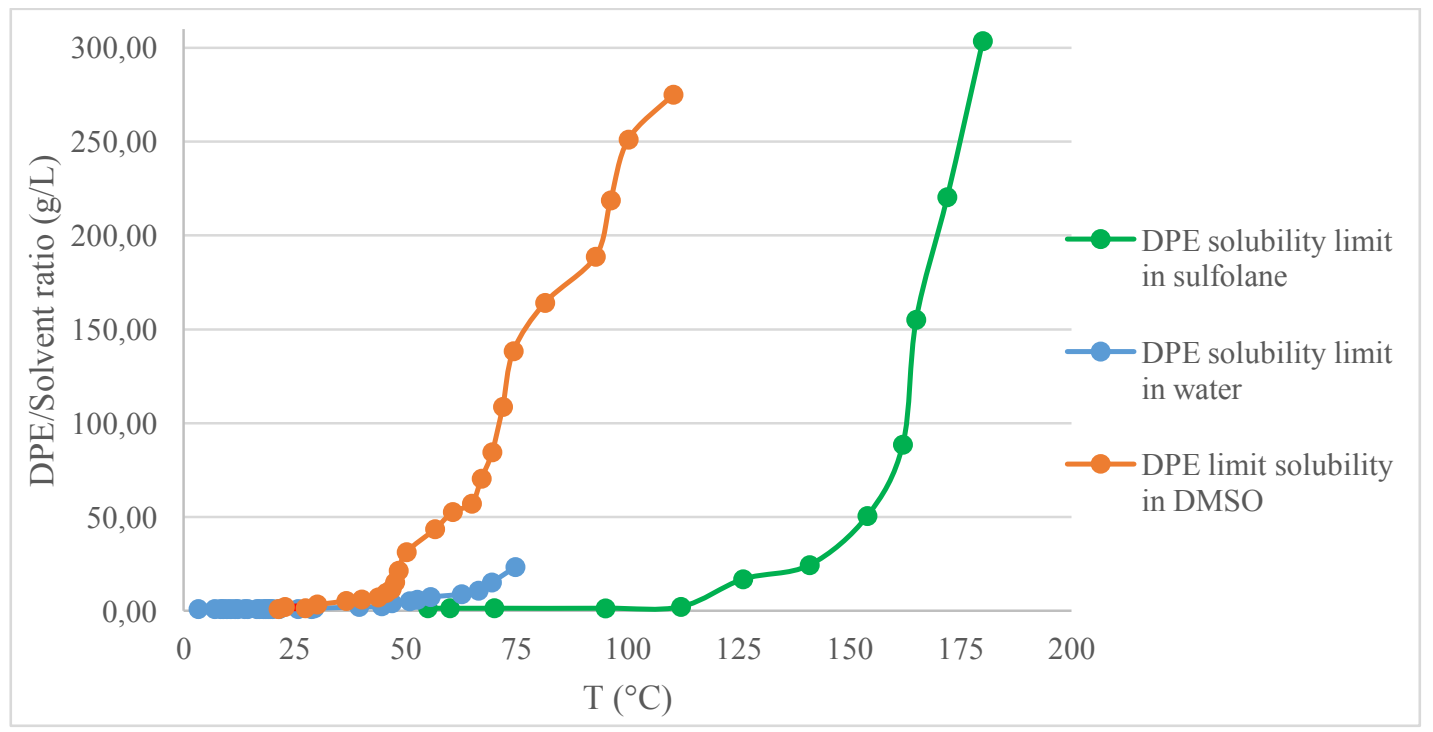

Figure 4: Limit solubility of DPE in sulfolane, water and DMSO. 
DPE is slightly soluble in water $\left(15 \mathrm{~g} / \mathrm{L}\right.$ at $70{ }^{\circ} \mathrm{C}$, blue curve on figure 4$)$, in dimethylsulfoxyde (DMSO; $15 \mathrm{~g} / \mathrm{L}$ at $45{ }^{\circ} \mathrm{C}$, orange curve on figure 4$)$ and in sulfolane $\left(20 \mathrm{~g} / \mathrm{L}\right.$ at $140{ }^{\circ} \mathrm{C}$, green curve on figure 4).

Physicochemical properties of those polyols represented an issue regarding the dimerization implementation and the quantitative analysis of the reaction medium. A suitable dosage procedure was developed involving polyols derivatization (scheme 4) and gas chromatography analyses (dosage from calibration range). Details of the development and the procedure are available in supporting information.

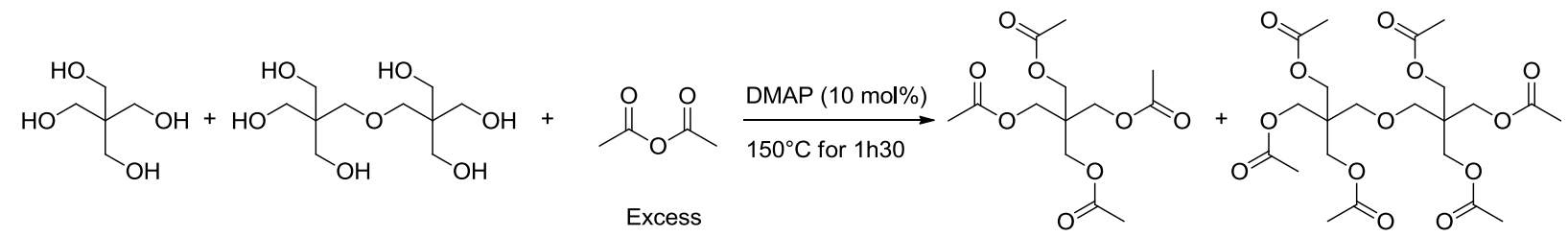

Scheme 4: PE and DPE acetylation with an excess of acetic anhydride catalyzed by DMAP Once the analysis method was determined, optimization of PE dimerization parameters in batch autoclave reactor was carried out.

\section{PE dimerization in batch autoclave reactor study}

From literature study, several parameters that could influence the outcome of the dimerization reaction were highlighted such as the presence of solvent, the acid catalyst, the reaction temperature and the presence of water throughout the synthesis.

In order to get further information, the influence of the solvent on both PE conversion and DPE selectivity was first studied in autoclave reactor with mechanical stirring (table 3). 
Table 3: Influence of the solvent on DPE selectivity and PE conversion - Dimerization performed with $0.1 \mathrm{~mol} \%$ of sulfuric acid for $16 \mathrm{~h}$ at $140{ }^{\circ} \mathrm{C}^{\mathrm{a}}$

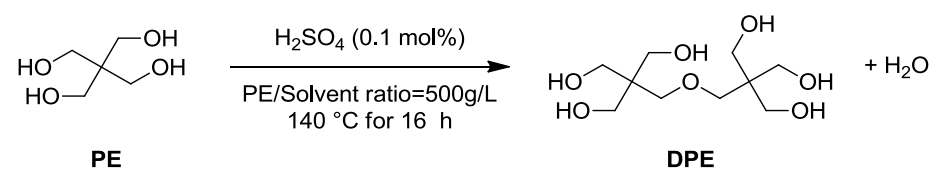

\begin{tabular}{|c|c|c|c|c|c|}
\hline Entry & Solvent & $\begin{array}{r}\text { PE } \\
\text { soluble }\end{array}$ & $\begin{array}{l}\text { PE conversion } \\
(\%)^{b}\end{array}$ & $\begin{array}{c}\text { DPE } \\
\text { yield }(\%)^{b}\end{array}$ & $\begin{array}{c}\text { DPE } \\
\text { selectivity }(\%)\end{array}$ \\
\hline 1 & Tetralin & Not & 14 & 0.2 & 1.4 \\
\hline 2 & CPME & Not & 15 & 0 & 0 \\
\hline 3 & 2-methylbutan-2ol & Not & 0.4 & 0.06 & 15 \\
\hline 4 & NMP & Not & 11 & 0.2 & 1.8 \\
\hline 5 & DMI & Not & 6 & 0 & 0 \\
\hline 6 & Sulfolane & Partially & 47 & 20 & 43 \\
\hline 7 & DMSO & Totally & 19 & 7 & 37 \\
\hline 8 & Water & Totally & 2.5 & 0.1 & 2.5 \\
\hline
\end{tabular}

${ }^{a}$ Reaction conditions: Autoclave reactor $(250 \mathrm{~mL}), \mathrm{PE}(0.22 \mathrm{~mol}, 30 \mathrm{~g})$, solvent $(60 \mathrm{~mL}$, $\mathrm{PE} /$ Solvent ratio $=500 \mathrm{~g} / \mathrm{L}), \mathrm{H}_{2} \mathrm{SO}_{4}(0.1 \mathrm{~mol} \%, 11.8 \mu \mathrm{L}), 140{ }^{\circ} \mathrm{C}, 16$ hours. ${ }^{\mathrm{b}}$ Determined by GPC following the method detailed in supporting information.

Syntheses achieved in solvents in which PE is not soluble such as tetralin, cyclopentyl methyl ether (CPME), 2-methylbutan-2ol, N-methyl-2-pyrrolidone (NMP) and 1,3-dimethyl-2- 
imidazolidinone (DMI), converted a small amount of pentaerythritol (from 0.4 to $15 \%$ ) in favour of side-products since no DPE was observed (table 3, entries 1 to 5). Dimerization reaction in sulfolane converted $47 \%$ of pentaerythritol for $43 \%$ DPE selectivity (table 3 , entry 6 ). At this temperature, $\mathrm{PE}$ is in suspension in sulfolane, $\mathrm{PE}$ limit solubility in sulfolane at $140{ }^{\circ} \mathrm{C}$ is 250 $\mathrm{g} / \mathrm{L}$ (green curve on figure 3). Thus, PE in suspension could be considered as a PE reservoir which could continuously feed the system during the dimerization. Conversely, using a solvent in which PE is totally soluble seems inappropriate since the reaction performed in DMSO converted $19 \%$ of PE for $37 \%$ DPE selectivity (table 3, entry 7 ) and in water converted only $2.5 \%$ of PE in favour of $0.1 \%$ of DPE (table 3 , entry 8 ).

Using a solvent in which PE is partially soluble demonstrated its beneficial impact on DPE selectivity. Sulfolane have therefore been preferred as solvent for dimerization reaction from PE. Solubility of PE in the solvent should be an important parameter throughout PE dimerization in acid conditions. Hence, impact of PE/Sulfolane ratio was next investigated (figure 5).

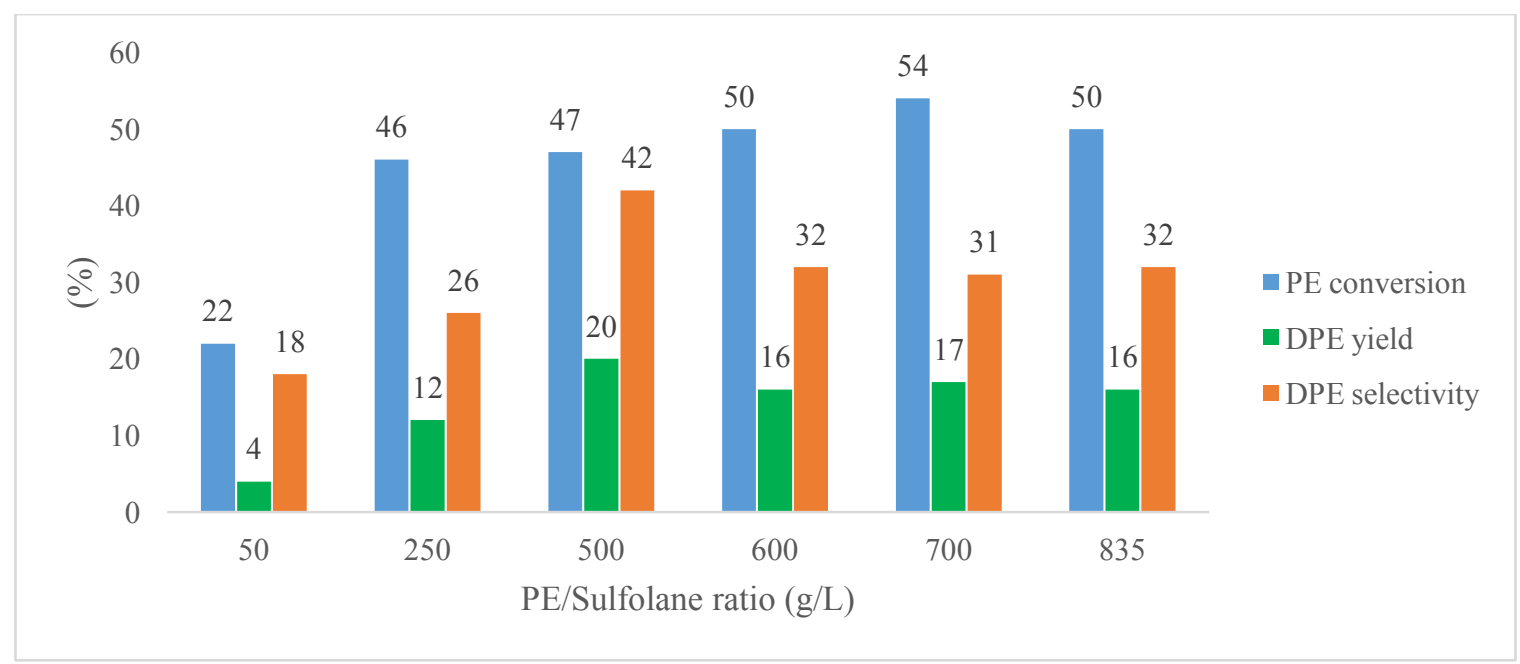

Figure 5: PE conversion and DPE selectivity Versus PE loading. Reaction conditions: Autoclave reactor, $\mathrm{PE}$, Sulfolane $(60 \mathrm{~mL}), \mathrm{H}_{2} \mathrm{SO}_{4},(0.1 \mathrm{~mol} \%), 140{ }^{\circ} \mathrm{C}, 16$ hours. The conversion of $\mathrm{PE}$ and 
yield of DPE were determined by gas chromatography following the method detailed in supporting information.

In a concentrated medium with $\mathrm{PE}$ fully soluble, which corresponds to $\mathrm{PE} /$ Sulfolane ratio at 250 $\mathrm{g} / \mathrm{L}$ (limit solubility at $140{ }^{\circ} \mathrm{C}$, green curve on figure 3), DPE selectivity reached $26 \%$ for $46 \%$ conversion of PE (figure 5). At iso-conversion of PE, DPE selectivity increased when $\mathrm{PE} /$ Sulfolane ratio increased from 250 to $500 \mathrm{~g} / \mathrm{L}$ (figure 5), thus confirming the importance of the presence of PE suspensions at the beginning of the synthesis. Indeed, at this temperature and for this concentration, PE exceeds the limit of solubility (green curve on figure 3). The selectivity dropped at $32 \%$ when increasing this ratio at $600 \mathrm{~g} / \mathrm{L}$ (figure 5 ). A maximum value at 31-32\% DPE selectivity is obtained for PE/Sulfolane ratios from 600 to $835 \mathrm{~g} / \mathrm{L}$ (figure 5). Experiment with 600 to $835 \mathrm{~g} / \mathrm{L}$ needed a high amount of PE which means that a high amount of acid catalyst was used in order to study the influence of PE loading at $0.1 \mathrm{~mol} \%$ of sulfuric acid. Throughout the study, the volume of sulfolane was kept constant. Solutions which used PE/Sulfolane ratios from 600 to $835 \mathrm{~g} / \mathrm{L}$ were more concentrated in sulfuric acid. This could explain the fact that side-reactions, such as oligomerization from the dimer, were accelerated thereby decreasing DPE selectivity. Dimerization reaction from PE in suspensions were preferred, PE potentially acting as a reservoir throughout DPE synthesis. During PE loading study, side-reactions appeared to significantly affect DPE selectivity.

Nevertheless, the results obtained in autoclave reactor were difficult to compare due to some variances with this system. After addition of all the compounds, the reactor was sealed. A strip heater then ensured heating. This method induced time variations during the temperature rise, from $15 \mathrm{~min}$ to $2 \mathrm{~h}$, depending of the targeted temperature. Moreover, the maximum temperature provided by this system was $160{ }^{\circ} \mathrm{C}$. Changing the equipment was proposed in order to use one 
in which the addition of acid catalyst could be realized when system is stabilized at the target temperature. Thus, optimization of the parameters was pursued in a glass reactor.

\section{Transposition from autoclave reactor to glass reactor}

Transposition process was investigated in order to both scale-up (realize a 140 grams scale process) and to avoid variances from synthesis performed in autoclave reactor which could influence the results. Hence, the optimal conditions previously determined in autoclave reactors were directly transposed into glass reactor (figure 6).

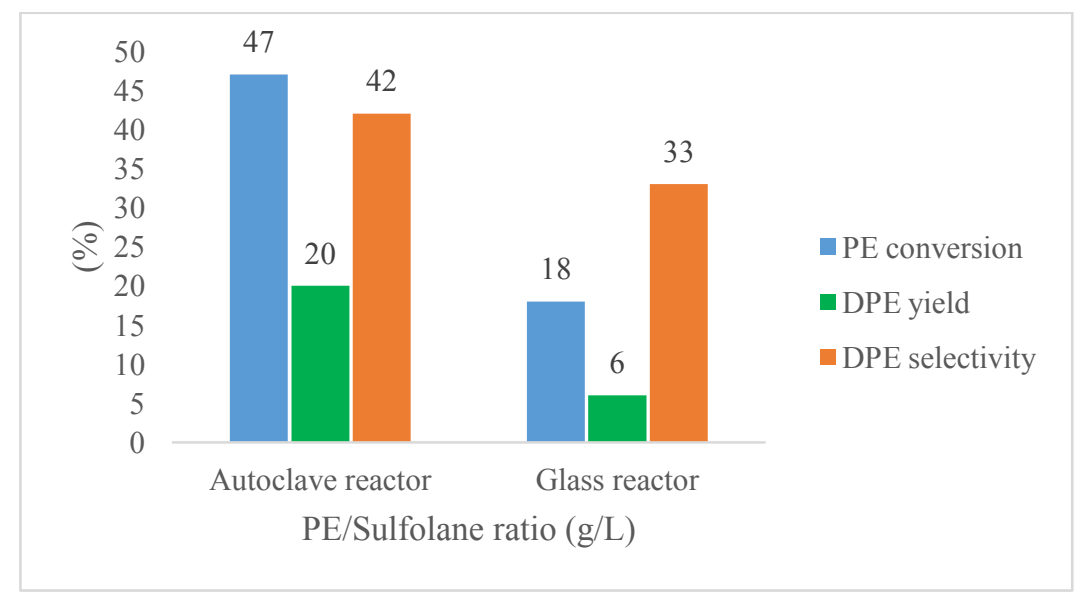

Figure 6: Process transposition from autoclave reactor to glass reactor. Reaction conditions: Autoclave reactor ${ }^{\mathrm{a}} v s$. Glass reactor ${ }^{\mathrm{b}}, \mathrm{PE}\left(30 \mathrm{~g}^{\mathrm{a}}\right.$ and $\left.15 \mathrm{~g}^{\mathrm{b}}\right)$, Sulfolane $\left(60 \mathrm{~mL}^{\mathrm{a}}\right.$ and $\left.30 \mathrm{~mL}^{\mathrm{b}}\right), \mathrm{H}_{2} \mathrm{SO}_{4}$, $(0.1 \mathrm{~mol} \%), 140{ }^{\circ} \mathrm{C}, 16$ hours., The conversion of PE and yield of DPE were determined by gas chromatography following the method detailed in supporting information.

Performing the synthesis in glass reactor from the optimal reaction conditions determined in autoclave reactor, reduced drastically the PE conversion from 47 to $18 \%$ (figure 6). Moreover, DPE yield decreased from $20 \%$ for the synthesis carried out in autoclave reactor to $6 \%$ for the synthesis realized in a glass reactor. Optimal conditions identified in autoclave reactor could not 
be directly transposed in a glass reactor. Once optimization of the reaction parameters realized, one more parameter will be further studied the effect of the equipment on DPE selectivity.

In order to evaluate the influence of the temperature as well the quantity of acid on both PE conversion and DPE selectivity in a glass reactor, a new set of experiment was accomplished (table 4). For this study, the target conversion of PE was 50\%.

Table 4: Influence of the temperature in glass reactor ${ }^{\mathrm{a}}$

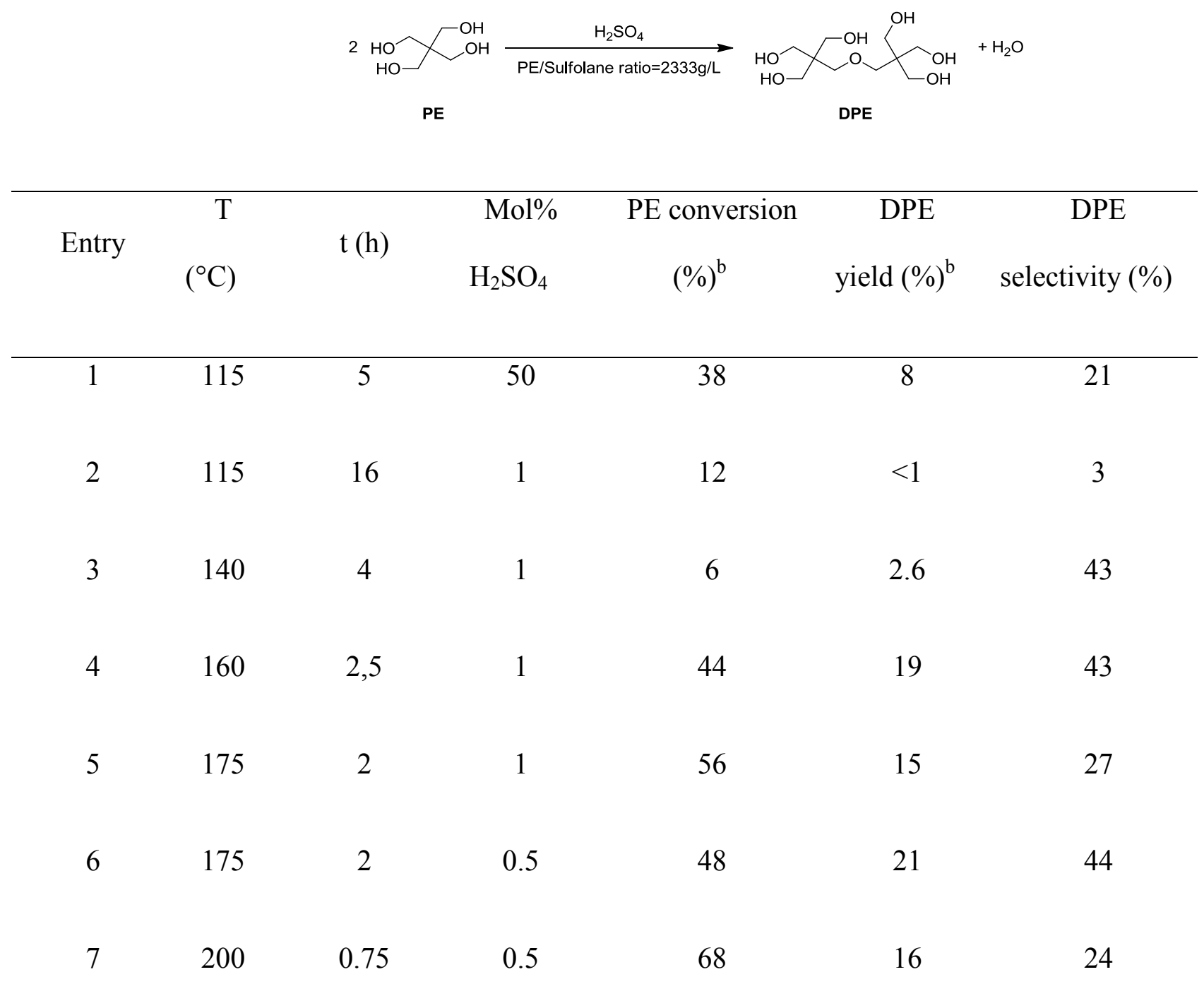


${ }^{a}$ Reaction conditions: Glass reactor $(500 \mathrm{~mL})$, PE $(1.02 \mathrm{~mol}, 140 \mathrm{~g})$, Sulfolane $(60 \mathrm{~mL}$, $\mathrm{PE} /$ Sulfolane ratio=2333 $\mathrm{g} / \mathrm{L}$ ), $\mathrm{H}_{2} \mathrm{SO}_{4} \cdot{ }^{\mathrm{b}}$ Determined by gas chromatography following the method detailed in supporting information.

Synthesis performed at $115^{\circ} \mathrm{C}$ for $5 \mathrm{~h}$ using $50 \mathrm{~mol} \%$ of sulphuric acid converted $38 \%$ in favour of $21 \%$ DPE selectivity (table 4 , entry 1). This high quantity of acid was decreased from 50 $\mathrm{mol} \%$ to $1 \mathrm{~mol} \%$. As we were waiting a decrease of the rate of the reaction, simultaneously, the reaction time was increased from 5 to $16 \mathrm{~h}$ in order to compare entries 1 and 2 when a same amount of PE was transformed (around 40\%). Nevertheless, a low amount of PE was converted $(12 \%)$ in favour of side-reactions since only less $1 \%$ of DPE was obtained (table 4, entry 2$)$. It demonstrated that longer reaction time promotes side-reactions. Then, temperature was increased to $140{ }^{\circ} \mathrm{C}$ for $4 \mathrm{~h}$ reaction time with $1 \mathrm{~mol} \%$ of acid. Those conditions converted only $6 \%$ of PE into $43 \%$ DPE selectivity (table 4 , entry 3 ). Increasing temperature from $140{ }^{\circ} \mathrm{C}$ to $160{ }^{\circ} \mathrm{C}$ and decreasing reaction time from 4 to $2 \mathrm{~h} 30$ achieved conversion of $44 \%$ of PE into $43 \%$ DPE selectivity (table 4 , entry 4). Thus, temperature was increased to $175{ }^{\circ} \mathrm{C}$ and in the meanwhile reaction duration was decreased from $2 \mathrm{~h} 30$ to $2 \mathrm{~h}$ : $56 \%$ of PE was converted into $27 \%$ DPE selectivity (table 4, entry 5). Decreasing by half the amount of sulfuric acid at $175{ }^{\circ} \mathrm{C}$, DPE selectivity reached $44 \%$ for $48 \%$ PE conversion (table 4 , entry 6 ). High temperature with low amounts of acid catalyst appeared to be favourable to DPE selectivity. Nevertheless, rising the temperature at $200{ }^{\circ} \mathrm{C}$ while decreasing at $0.5 \mathrm{~mol} \%$ and $0.01 \mathrm{~mol} \%$ of sulfuric acid, DPE selectivity fell to $24 \%$ and $15 \%$ for PE conversion of 68 and $57 \%$ (table 4 , entries 7 and 8 ). At high temperature $\left(>175^{\circ} \mathrm{C}\right)$, DPE rapidly underwent oligomerization. Syntheses performed at higher temperatures allow solubilizing a higher amount of PE in sulfolane: as observed 
previously, this growth is exponential from $100{ }^{\circ} \mathrm{C}$ (green curve on figure 3). This shows that a high quantity of $\mathrm{PE}$ is solubilized in reaction medium for dimerization reactions realized at 200 ${ }^{\circ} \mathrm{C}$ for a PE/Sulfolane ratio $=2333 \mathrm{~g} / \mathrm{L}$. Previous study in autoclave reactor demonstrated that high concentration solubilized in the solvent favours side reactions such as oligomerization of molecules with high molecular weight (higher than trimer).

The influence of a further increase of PE/Sulfolane ratio on DPE selectivity and the importance of PE in suspension at the beginning of the reaction were then studied (figure 7).

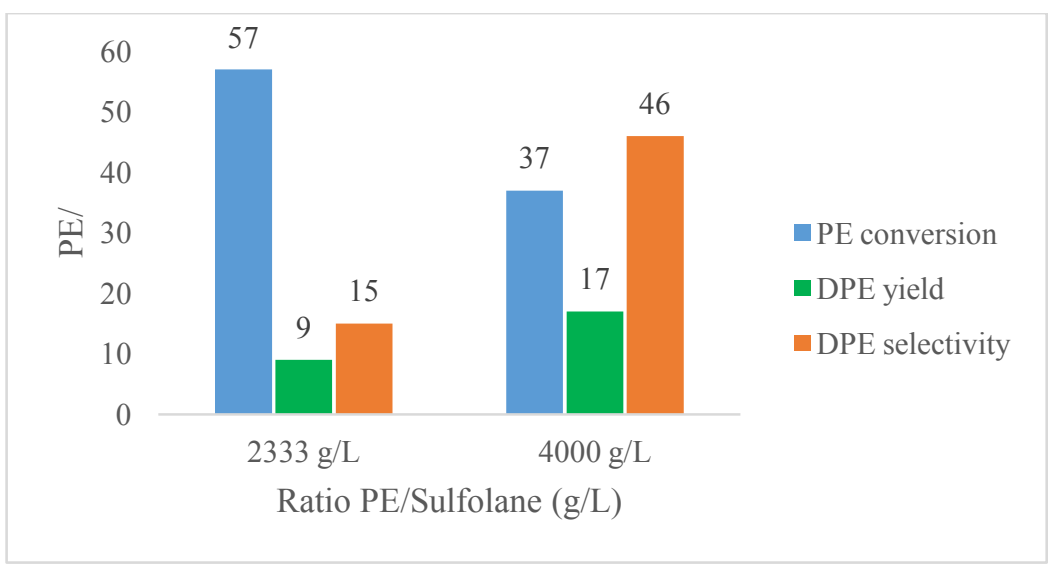

Figure 7: PE/Sulfolane ratio study. Reaction conditions: Glass reactor, PE, Sulfolane $(60 \mathrm{~mL})$, $\mathrm{H}_{2} \mathrm{SO}_{4}(0,1 \mathrm{~mol} \%), 200{ }^{\circ} \mathrm{C}, 45 \mathrm{~min}$. The conversion of PE and yield of DPE were determined by gas chromatography following the method detailed in supporting information.

As noted above, the PE/Sulfolane ratio is an important parameter for dimerization reaction of PE under acidic conditions. Synthesis performed with high soluble concentration of PE in sulfolane (PE/Sulfolane ratio at $2333 \mathrm{~g} / \mathrm{L}$ ) converted $57 \%$ of PE in favour of $15 \%$ DPE selectivity while the synthesis realized with presence of PE suspension (PE/Sulfolane ratio at $4000 \mathrm{~g} / \mathrm{L}$ ) transformed $37 \%$ of PE for $46 \%$ DPE selectivity (figure 7). PE saturation of the system at the beginning of the dimerization has been found essential to reach an acceptable DPE selectivity. 
$\mathrm{PE} /$ Sulfolane ratio needs to be adjusted according to the temperature. At high temperature, less solvent is required which could positively impact the economical evaluation.

In conclusion, optimal temperature for dimerization from PE determined was $175{ }^{\circ} \mathrm{C}$. A low amount of acid catalyst $(0.1 \mathrm{~mol} \%)$ was required for DPE production at $175^{\circ} \mathrm{C}$. At this point, nature and strength of acid catalysts was not investigated yet. Consequently, a screening of acid catalyst was performed from weak acid to superacid (table 5).

Table 5: Screening of acid catalysts ${ }^{\mathrm{a}}$

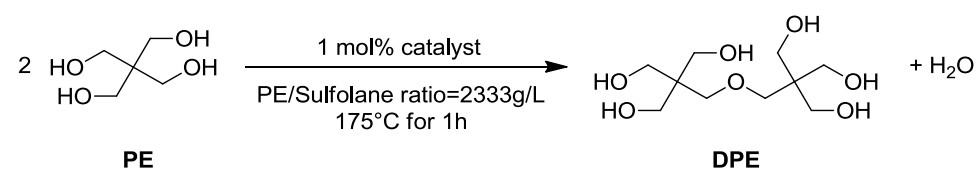

\begin{tabular}{|c|c|c|c|c|}
\hline Entry & Catalyst & $\begin{array}{c}\text { PE conversion } \\
(\%)^{\mathrm{b}}\end{array}$ & DPE yield $(\%)^{b}$ & $\begin{array}{c}\text { DPE } \\
\text { selectivity }(\%)\end{array}$ \\
\hline 1 & No & 11 & 0 & 0 \\
\hline $2^{c}$ & $\begin{array}{c}\mathrm{H}_{3} \mathrm{PO}_{4} \\
\text { (solution } 85 \% \text { ) }\end{array}$ & 30 & 14 & 47 \\
\hline & $\mathrm{H}_{3} \mathrm{PO}_{4}$ & & & \\
\hline $3^{c}$ & (solid) & 43 & 16 & 37 \\
\hline $4^{c}$ & $\mathrm{H}_{3} \mathrm{PO}_{3}$ & 39 & 17 & 44 \\
\hline 5 & $\mathrm{CH}_{3}-\mathrm{SO}_{3} \mathrm{H}$ & 38 & 14 & 37 \\
\hline
\end{tabular}


6

7

8
$\mathrm{H}_{2} \mathrm{SO}_{4}$

PTSA

$\mathrm{CF}_{3}-\mathrm{SO}_{3} \mathrm{H}$
40

47

53
21

15

8
52

31

15

${ }^{a}$ Reaction conditions: Glass reactor $(500 \mathrm{~mL}), \mathrm{PE}(1.03 \mathrm{~mol}, 140 \mathrm{~g})$, Sulfolane $(60 \mathrm{~mL}$, $\mathrm{PE} /$ Sulfolane ratio $=2333 \mathrm{~g} / \mathrm{L})$, acid catalyst $(1 \mathrm{~mol} \%), 175{ }^{\circ} \mathrm{C}, 1$ hour. ${ }^{b}$ Determined by gas chromatography following the method detailed in supporting information. ${ }^{\mathrm{c}}$ Reaction for 20 hours.

Synthesis performed with phosphoric acid in solution (85\%) and solid respectively converted $30 \%$ and $43 \%$ of PE in favour of $47 \%$ and $37 \%$ DPE selectivity (table 5, entries 2 and 3). This difference reflected the significant impact of water presence on the reactivity. Water appeared to slow down PE conversion. This observation is coherent because direct dimerization under acidic conditions consists to PE dehydration (figure 2). Synthesis realized with phosphorous acid converted $39 \%$ of PE for $44 \%$ DPE selectivity (table 5, entry 4). Using methanesulfonic acid, $38 \%$ of PE was converted for $37 \%$ DPE selectivity (table 5, entry 5). Then, the best DPE selectivity (52\%) was obtained by using sulfuric acid (table 5, entry 6). Using stronger acids lead to the decrease of DPE selectivity at $31 \%$ for PTSA and $15 \%$ for triflic acid for PE conversion respectively at 47 and 53\% (table 5, entries 7 and 8 ). These experiments showed that the nature of acid has a strong influence on both PE conversion and DPE selectivity. For similar PE conversion, syntheses performed with weaker acids promoted higher DPE selectivity (from 37 to 47\%) whereas the use of super acids favoured side reactions since DPE selectivity less than $30 \%$ were achieved. Sulfuric acid was remained as acid catalyst since it presented the best results regarding both PE conversion and DPE selectivity. 
Subsequently, the effect of the loading of sulfuric acid was probed (figure 8).

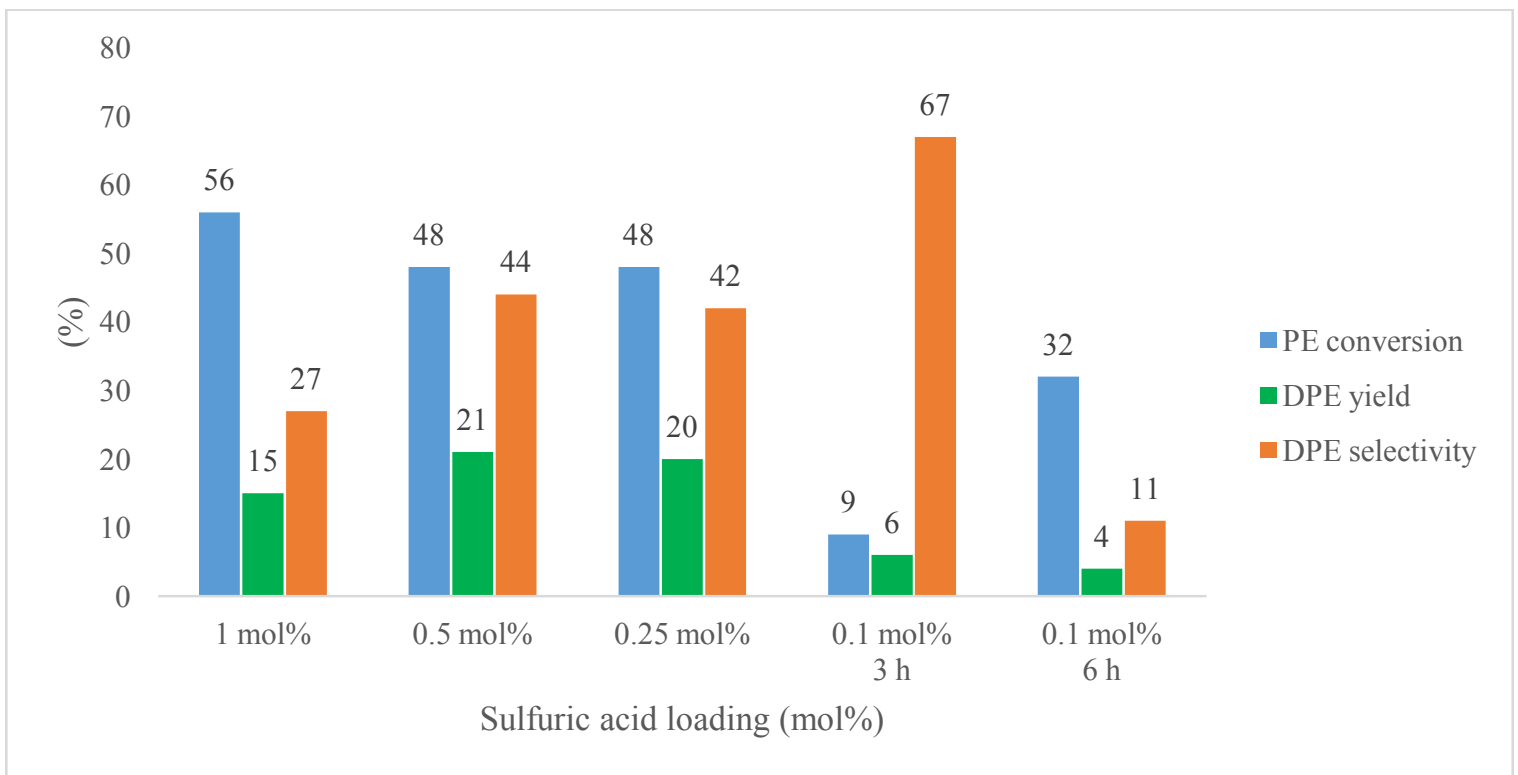

Figure 8: Catalyst loading study. Reaction conditions: Glass reactor $(500 \mathrm{~mL}), \mathrm{PE}(1.03 \mathrm{~mol}$, $140 \mathrm{~g})$, Sulfolane $(60 \mathrm{~mL}$, PE/Sulfolane ratio $=2333 \mathrm{~g} / \mathrm{L}), \mathrm{H}_{2} \mathrm{SO}_{4}, 175{ }^{\circ} \mathrm{C}, 2$ hours. The conversion of PE and yield of DPE were determined by gas chromatography following the method detailed in supporting information.

Using $1 \mathrm{~mol} \%$ of sulfuric acid at $175{ }^{\circ} \mathrm{C}$, PE conversion reached $56 \%$ but DPE selectivity was only $27 \%$ (figure 8 ). This result shows the promotion of oligomers (with higher molecular weight than DPE and TPE) at high temperature with high acid catalyst loading. Reducing by two this amount, reduced a little PE conversion from 56 to $48 \%$ but improved DPE selectivity to $44 \%$. Syntheses performed with 0.5 and $0.25 \mathrm{~mol} \%$ of sulfuric acid were quite similar. The loading was then drastically reduced to $0.1 \mathrm{~mol} \%$ and longer reaction time was used $(3 \mathrm{~h})$. In that case, $9 \%$ of PE was converted into 6\% DPE yield with an excellent DPE selectivity of $70 \%$. Synthesis with $0.1 \mathrm{~mol} \%$ was carried out longer in order to evaluate DPE selectivity when more PE was converted. Nevertheless, under these conditions, DPE selectivity has dropped to $11 \%$ when PE conversion increased to $32 \%$. Loading of sulfuric acid was therefore kept at $0.5 \mathrm{~mol} \%$. 
All the parameters that could influence the outcome of the reaction have been studied but DPE selectivity maximum at about $50 \%$ for $50 \%$ PE conversion. In order to get further information, the reaction was followed over time. Taking samples in the same reaction medium over time was not possible because of the heterogeneity of the system. Consequently, separate experiments were carried out and stopped at different times (figure 9).

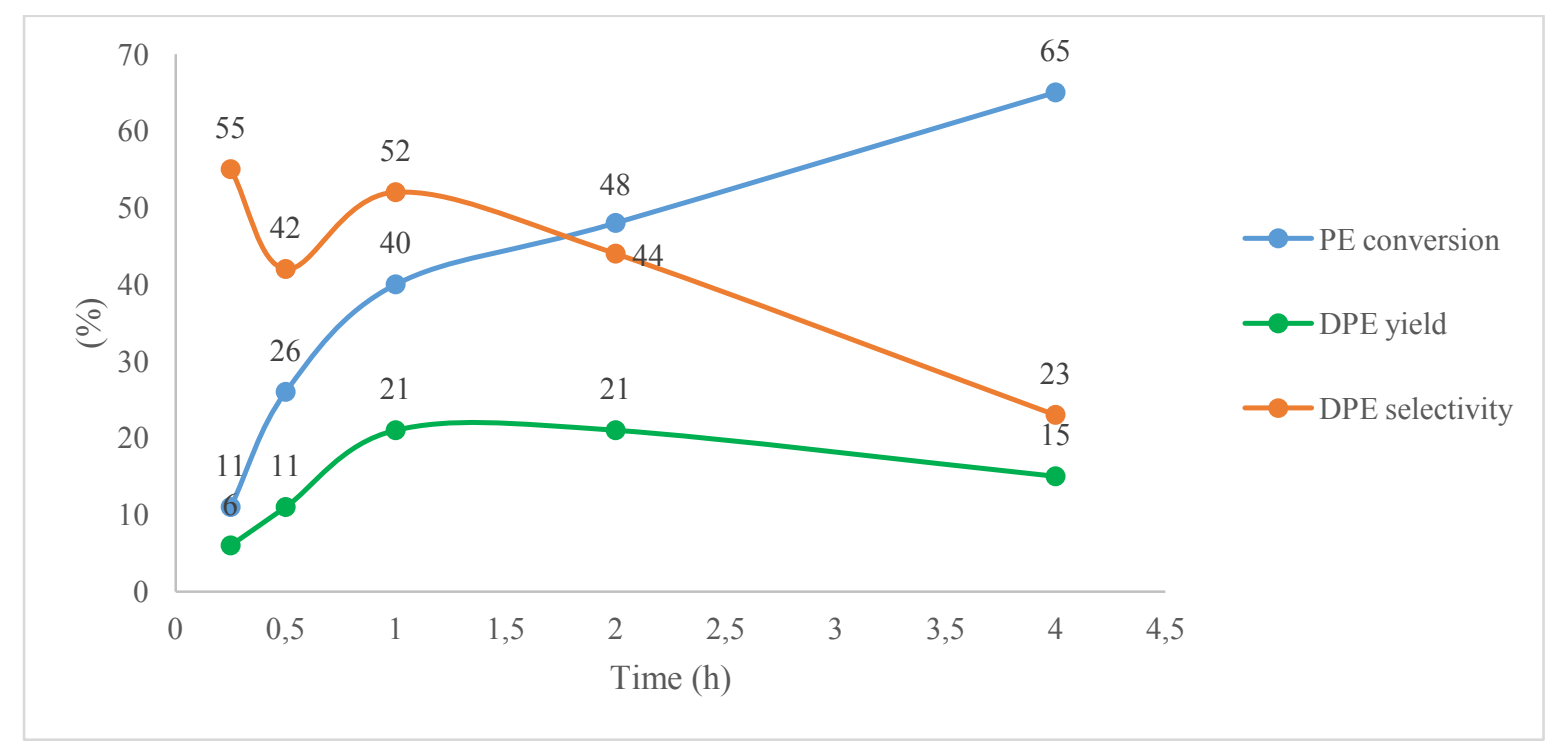

Figure 9: Conversion of PE and DPE selectivity over time. Reaction conditions: Glass reactor $(500 \mathrm{~mL}), \mathrm{PE}(1.03 \mathrm{~mol}, 140 \mathrm{~g})$, Sulfolane $\left(60 \mathrm{~mL}, \mathrm{PE} / \mathrm{Sulfolane}\right.$ ratio=2333 g/L), $\mathrm{H}_{2} \mathrm{SO}_{4}(0.5$ $\mathrm{mol} \%), 175^{\circ} \mathrm{C}$. The conversion of PE and yield of DPE were determined by gas chromatography following the method detailed in supporting information.

After only 60 minutes, the conversion was $40 \%$ and the DPE selectivity almost reached $52 \%$. Then, the DPE selectivity progressively decreased to $23 \%$. These results indicate that even at very low PE conversion, DPE selectivity is not total and side-reactions occurred because of the introduction of acid catalyst. Following the reaction over time also shows the DPE selectivity falling after 50\% PE conversion. 
DPE yield of $21 \%$ was obtained for $1 \mathrm{~h}$ and $1 \mathrm{~h} 30$ reaction time, with higher DPE selectivity after $1 \mathrm{~h}$. Thus, the reaction time selected for dimerization reaction performed at $175{ }^{\circ} \mathrm{C}$ with 0.5 mol\% was $1 \mathrm{~h}$.

The proper balance between reaction time, temperature, catalyst (nature and loading) and solvent (nature and loading) was found: dimerization reaction will henceforth be carried out with a $\mathrm{PE} /$ Sulfolane ratio of $2333 \mathrm{~g} / \mathrm{L}, 0.5 \mathrm{~mol} \%$ of sulfuric acid at $175{ }^{\circ} \mathrm{C}$ for $1 \mathrm{~h}$. The best DPE titrated yield in these conditions was $21 \%$ for $40 \%$ PE conversion.

\section{Water effect on direct dimerization of PE study}

From the beginning of this study, water presence in the reaction medium appeared to greatly affect the reactivity. Water is produced during dimerization from PE since DPE is formed by condensation. A study was realized by varying the quantity of water at the beginning of the synthesis in order to assess its influence on DPE selectivity (figure 10).

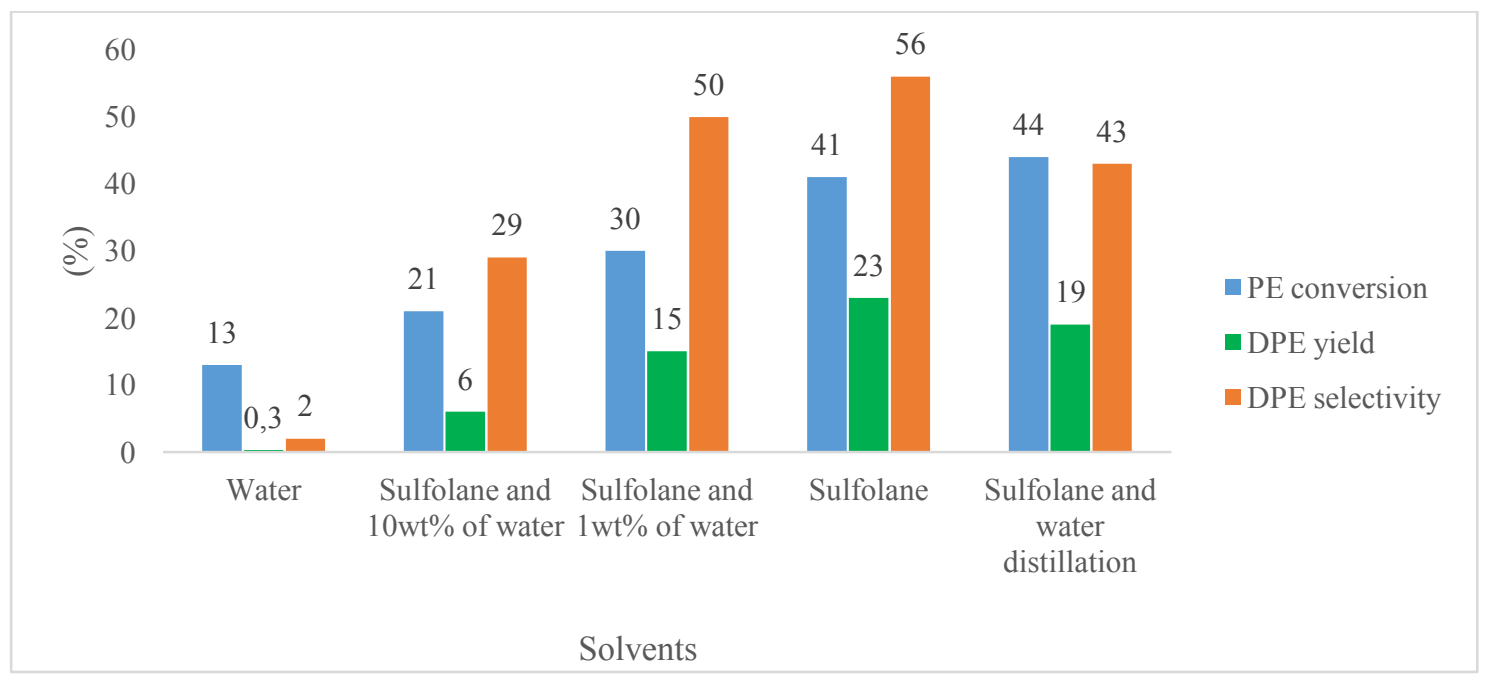

Figure 10: Influence of water on DPE selectivity study. Reaction conditions: Autoclave reactor, PE (0.88 mol, $120 \mathrm{~g})$, Sulfolane (51 mL, PE/Sulfolane ratio=2333 g/L), $\mathrm{H}_{2} \mathrm{SO}_{4}(0.1 \mathrm{~mol} \%), 175$ 
${ }^{\circ} \mathrm{C}, 1$ hour. The conversion of PE and yield of DPE were determined by gas chromatography following the method detailed in supporting information.

Synthesis carried out in water as solvent converted $13 \%$ of PE and produced only $0.3 \%$ of DPE (figure 10). DPE selectivity increased from 2 to $29 \%$ by using water as co-solvent with sulfolane (10 wt $\%$ of water). PE was converted at $21 \%$, which was twice as less the synthesis performed with only sulfolane. DPE yield increased when water loading was decreased. Indeed, 30\% of PE were converted, giving a $15 \%$ DPE yield when only $1 \mathrm{wt} \%$ of water was introduced at the beginning of the reaction. Nevertheless, best DPE selectivity $(56 \%)$ for best PE conversion (41\%) was obtained when sulfolane was used without water. This shows that addition of high quantity of water is not beneficial to promote DPE selectivity. This is probably because water as solvent or co-solvent solubilizes more PE than in the system exempt of water and reaction medium became more reactive. Those results show also that water drastically reduces PE conversion. Distillation of water converted $44 \%$ of PE into $43 \%$ DPE selectivity. This trial demonstrated that a very small quantity of water (for example, the one produced within the synthesis) seems important regarding DPE selectivity. A very small quantity of water could slow down oxetanes polymerization by opening the highly reactive oxetane oxonium species as shown in the proposed mechanism (figure 2).

This study confirmed the observation of Toshio Okuhara et al.. ${ }^{12}$ They noted influence of water on polyols reactivity. Water presence since the beginning of the reaction decreased PE reactivity and DPE yield. 


\section{Polyols separation study}

After optimization of the reaction parameters, several polyol separation methods were evaluated in order to remove solid DPE from the reaction medium and to retain PE in the filtrate (figure 11). Method 1 was realized at the end of DPE synthesis performed with $1 \mathrm{~mol} \%$ sulfuric acid in sulfolane (PE/Sulfolane ratio of $500 \mathrm{~g} / \mathrm{L})$ at $140{ }^{\circ} \mathrm{C}$ for $16 \mathrm{~h}$. Method 2 and 3 were carried out at the end of PE dimerization with 1 and $0.5 \mathrm{~mol} \%$ of sulfuric acid in sulfolane (PE/Sulfolane ratio of $2333 \mathrm{~g} / \mathrm{L}$ ) at $175{ }^{\circ} \mathrm{C}$ for $1 \mathrm{~h}$. Methods 4 and 5 were realized directly at the end of PE dimerization with 0.25 and $0.5 \mathrm{~mol} \%$ of sulfuric acid in sulfolane (PE/Sulfolane ratio of 2333 $\mathrm{g} / \mathrm{L})$ at $175^{\circ} \mathrm{C}$ for $30 \mathrm{~min}$ and $1 \mathrm{~h}$.

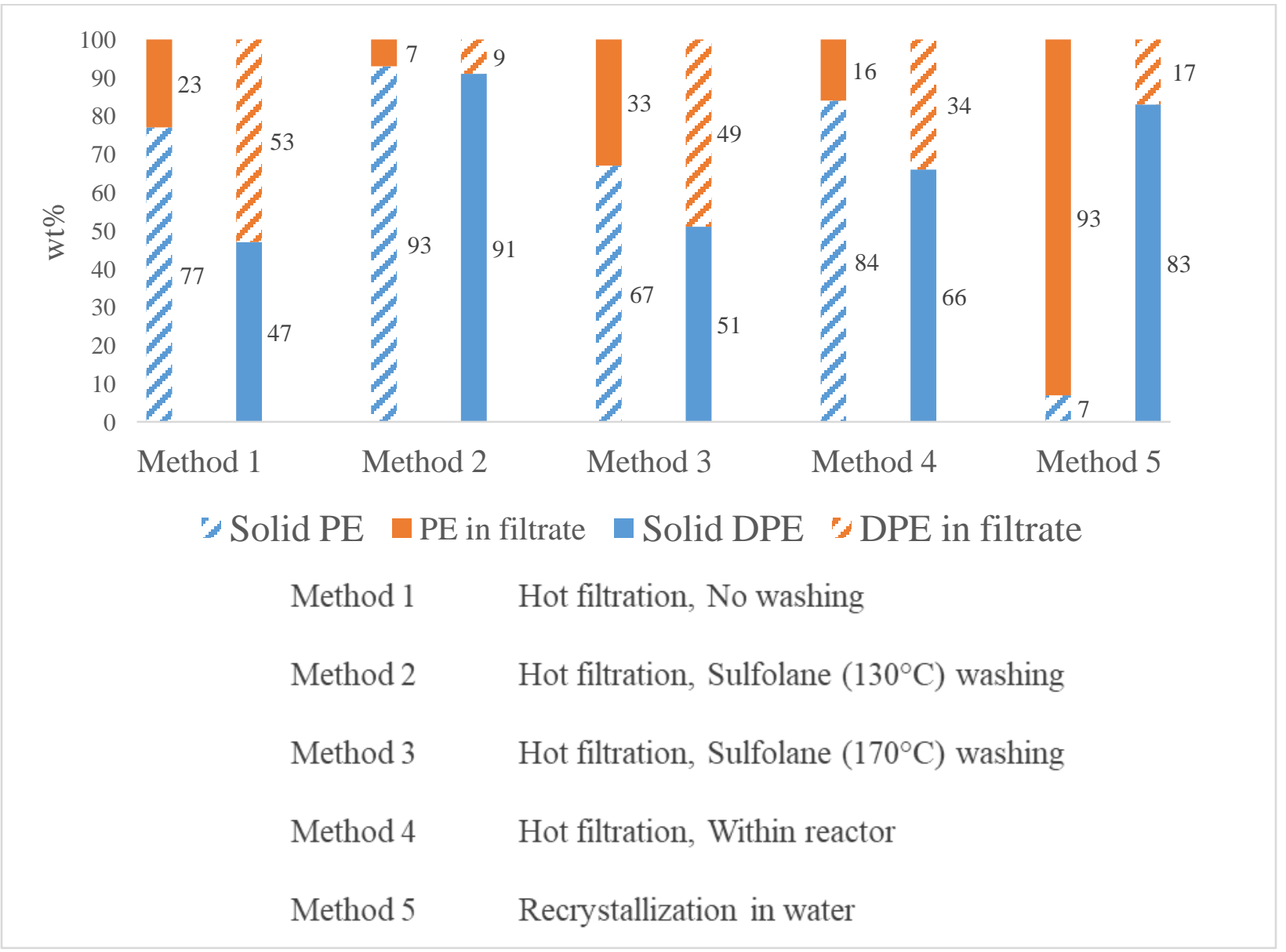


Figure 11: Separation methods study (details regarding separation methods study are available in the supporting information)

The first method consisted in filtrating the reaction medium without sulfolane washing of the solid. This method removed a majority of solid PE (77 wt\%). DPE was divided in two equal parts since $47 \mathrm{wt} \%$ was solid and $53 \mathrm{wt} \%$ was in the filtrate. Polyols were not separated with method 1 .

The second method consisted first in crystallizing DPE at $160{ }^{\circ} \mathrm{C}$ at the end of the synthesis. Below $160{ }^{\circ} \mathrm{C}$, crystallization of the entire reaction medium (PE, DPE and oligomers) was observed. After crystallization, the solid was filtered and washed with sulfolane $\left(130{ }^{\circ} \mathrm{C}\right)$. Almost all the polyols were solids since $93 \mathrm{wt} \%$ of PE and $91 \mathrm{wt} \%$ of DPE were solids. Polyols were not separated with method 2.

The third method followed the same instructions than method 2, excepted that sulfolane used for washing was at $170{ }^{\circ} \mathrm{C}$. Quantity of polyols in the filtrate were higher with sulfolane washing at $170{ }^{\circ} \mathrm{C}$ since 33 and $49 \mathrm{wt} \%$ of PE and DPE were in the liquid phase compared to 7 and $9 \mathrm{wt} \%$ with sulfolane washing at $130{ }^{\circ} \mathrm{C}$ (method 2$)$. Nevertheless, changing sulfolane temperature was not sufficient to separate the polyols from the reaction medium.

The fourth method consisted in adding a filter directly in the reaction medium and removing it. In that way, polyols were essentially removed as solids: $84 \mathrm{wt} \%$ of PE and $66 \mathrm{wt} \%$ of DPE were solids.

Finally, synthesis with recrystallization in water at the end allowed separating DPE from PE. This separation consisted of two fractional crystallization operation utilizing the difference of solubility of PE, DPE and oligomers in water. The first crystallization was realized at $30{ }^{\circ} \mathrm{C}$ for 
$24 \mathrm{~h}$ and separate oligomers $(\mathrm{n}=5$ and $\mathrm{n}=6)$ from the reaction medium. Then, reaction medium is concentrated by evaporating water and a second crystallization is performed at $30{ }^{\circ} \mathrm{C}$ for $24 \mathrm{~h}$. An acceptable separation was observed since $83 \mathrm{wt} \%$ of DPE was solid and $93 \mathrm{wt} \%$ of PE was still in the filtrate.

\section{DPE isolation study}

Once the separation method chosen, isolation of DPE at the end of PE dimerization under acidic conditions was performed following the block diagram on figure 12.

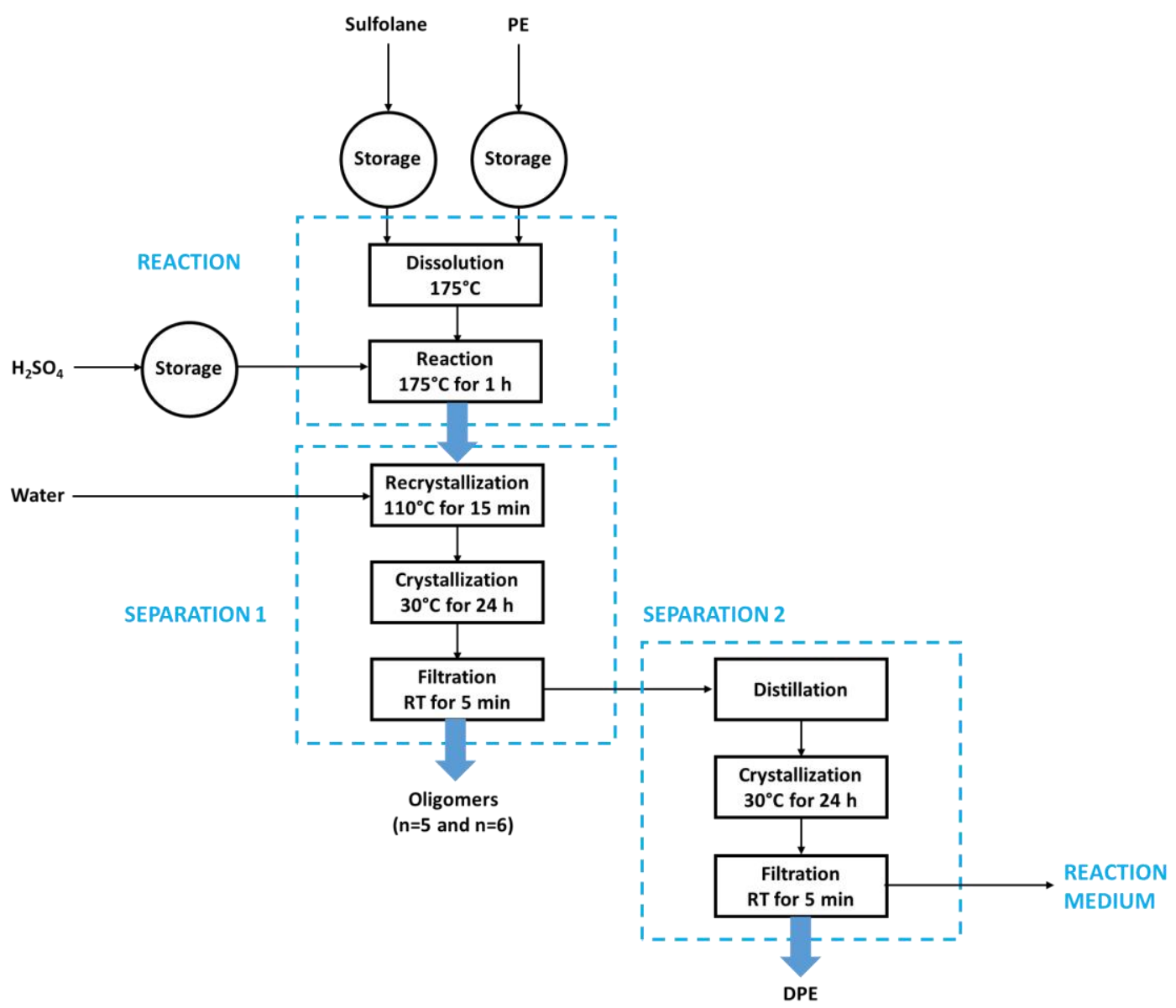

Figure 12: Block diagram regarding dimerization of PE under acidic conditions- Process steps 
The first stage consists in the formation of DPE when a relatively low amount of PE was converted (30-40\%). Following the optimized parameters, the synthesis required low amount of sulfuric acid $(0.5 \mathrm{~mol} \%, 0.5 \mathrm{~mL})$ and PE $(1.01 \mathrm{~mol}, 137.6 \mathrm{~g})$ in suspension in sulfolane $(60 \mathrm{~mL}$, $\mathrm{PE} /$ Sulfolane ratio $=2333 \mathrm{~g} / \mathrm{L}$ ). The reaction proceeds at $175^{\circ} \mathrm{C}$ for $60 \mathrm{~min}$.

Then, recrystallization of oligomers was realized in water $(250 \mathrm{~mL})$ at $100{ }^{\circ} \mathrm{C}$ for $15 \mathrm{~min}$. Temperature was cooled down at $30{ }^{\circ} \mathrm{C}$ and extra water was added $(750 \mathrm{~mL})$. Thus, crystallization was initiated with the addition of DPE ( $5 \mathrm{mmol}, 1.2 \mathrm{~g}$ ) and performed for $24 \mathrm{~h}$ at $30^{\circ} \mathrm{C}$. Solution was filtered. Solids (oligomers $\mathrm{n}=5$ and $\mathrm{n}=6$ on figure 12 ) were separated and the filtrate (filtrate 1) was concentrated (500 $\mathrm{mL}$ of water was removed). Another crystallization with DPE addition $(0.004 \mathrm{~mol}, 1 \mathrm{~g})$ was achieved at $30{ }^{\circ} \mathrm{C}$ for $24 \mathrm{~h}$. Solution from the second crystallization was filtered. $16 \%$ isolated DPE yield was obtained (20.0 g DPE) with $72 \%$ GPC purity (DPE on figure 12). Water $(500 \mathrm{~mL})$ was eliminated from the filtrate (filtrate 2$)$ in order to analyse the reaction medium which only contains PE, sulfuric acid and sulfolane. Only $28 \%$ of PE (99 g analysed in gas chromatography) were transformed during this synthesis and 7\% of lost was observed during the purification step (91.3 g of PE was retained). After all, DPE titrated yield for this synthesis was $19 \%$ for $28 \%$ titrated conversion of PE which correspond to $67 \%$ DPE selectivity. Nevertheless, $3 \%$ of DPE yield was lost during the purification which reduced the isolated DPE selectivity at $57 \%$.

\section{Conclusion}

Selective DPE synthesis from PE was studied under acidic conditions. The first approach, for PE dimerization, consisted in the use of only an acid $(50 \mathrm{~mol} \%)$ without additional solvent. Brief optimization of this reaction was performed with methanesulfonic acid, sulfuric acid, 
Armstrong's acid and triflic acid. The highest DPE selectivity, 77\%, was obtained when $47 \%$ of PE was converted using triflic acid at $120^{\circ} \mathrm{C}$ for $120 \mathrm{~min}$. Nevertheless, studies related to this pathway were not pursued in reason of the high quantity of acid used in these conditions.

However, this first study allowed us to identify the main challenges regarding PE dimerization under acidic conditions. The first issue is due to the physiochemical properties of polyols (nonsoluble in most of solvents and high melting point) which complicate the process implementation and require a high amount of energy. The second issue concerns polyols reactivity throughout the synthesis. For the PE dimerization at $120^{\circ} \mathrm{C}$ using $50 \mathrm{~mol} \%$ of $\mathrm{H}_{2} \mathrm{SO}_{4}$, the highest yield of DPE is obtained when $50 \%$ of PE is converted and beyond this conversion, DPE yield drastically decreased. We thought that this fall regarding DPE selectivity is essentially due to oxonium-oxetanes-polyol species (from PE, DPE and/or TPE) which are intermediates. The evolution of the DPE yield also demonstrated that even at very low PE conversion, side-reactions from the dimer and the monomer occurred from the beginning of the synthesis.

Thus, a second approach of PE dimerization, with solvent under acidic conditions, was proposed in an effort to solve those issues. Several polar and non-polar solvents were tested and the best DPE yield and PE conversion were obtained in sulfolane. After optimization of the reaction parameters in sulfolane, the best result obtained in batch reactor was $50 \%$ DPE selectivity for $50 \%$ PE conversion. The best DPE selectivity $(70 \%)$ was observed with a low conversion of PE (9\%). The same observations, determined in PE dimerization without additional solvent, were noticed in sulfolane. The main limit, during the PE dimerization under acidic conditions, is due to oxetanes polymerization from the beginning of the reaction which produce oligomers with high molecular weight (superior than trimer). 
Finally, to ensure the possibility of separating the desired product from the mixture, the best separation method was identified (recrystallization in water), the scale-up was then performed in the optimized conditions from $140 \mathrm{~g}$ of PE. At $175^{\circ} \mathrm{C}$ for $60 \mathrm{~min}$ using $0.5 \mathrm{~mol} \%$ of sulphuric acid in sulfolane (PE/Sulfolane ratio $=2333 \mathrm{~g} / \mathrm{L}), 68 \%$ of the $28 \%$ of converted PE were transformed into DPE. In these conditions, a 16\% isolated DPE yield was obtained.

\section{EXPERIMENTAL SECTION}

\section{General procedure for dimerization of PE without additional solvent under acidic conditions}

PE $(7.34 \mathrm{mmol}, 1 \mathrm{~g})$ and sulfuric acid $(50 \mathrm{~mol} \%, 0.36 \mathrm{~g}, 195.7 \mu \mathrm{L})$ were added in a $15 \mathrm{~mL}$ sealed tube $(\varnothing \mathrm{i}=2 \mathrm{~cm})$. Stirring was ensured by a bar magnet $(\mathrm{l}=1.4 \mathrm{~cm}$ and $\mathrm{h}=0.8 \mathrm{~cm})$. The sealed tube was added in a silicon oil bath at the target temperature (measured by a glass thermometer) and the reaction was performed. The reaction was stopped by removing the sealed tube from the heating and it was cooled down at room temperature. To finish, the reaction medium (solid) was transferred in a round bottom flask in order to be analyzed (following the quantitative method described previously). Derivatization using an excess of acetic anhydride and a catalytic amount of DMAP was carried out at $150^{\circ} \mathrm{C}$ for $1 \mathrm{~h} 30$. Then, solvents were evaporated, graduated flasks (first $100 \mathrm{~mL}$ as stock solution and dilution in $10 \mathrm{~mL}$ ) were prepared and acetylated reaction medium was analyzed in gas chromatography.

\section{General procedure for dimerization of $\mathrm{PE}$ under acidic conditions in glass reactor}


Sulfolane $(60 \mathrm{~mL}, \mathrm{PE} /$ Sulfolane ratio $=2333 \mathrm{~g} / \mathrm{L})$ and $\mathrm{PE}$ were added in a $500 \mathrm{~mL}$ three necked round bottom flask equipped of a $\mathrm{CaCl} 2$ guard (figure S18). Temperature was measured directly inside the reaction medium with a teflon thermometer. Then, reaction medium was heated at the target temperature $\left(175 \pm 5^{\circ} \mathrm{C}\right)$. Once the system stabilized, acid was added and reaction was performed for " $\mathrm{t}$ ".

\section{ASSOCIATED CONTENT}

Supporting Information. gas chromatography method, general procedures, optimization studies about dimerization of PE without additional solvent under acidic conditions, characterization data of polyols such as ${ }^{1} \mathrm{H}$ and ${ }^{13} \mathrm{C}$ NMR spectra, mass spectrometry, solubility tests and DSC analyses.

\section{AUTHOR INFORMATION}

\section{Corresponding Author}

*E-mail: estelle.metay@univ-lyon1.fr

ORCID

Estelle Metay: +33(0)-472-4448-507

* E-mail: marc.lemaire.chimie@univ-lyon1.fr

\section{Notes}

The authors declare no competing financial interest.

\section{ACKNOWLEDGMENT}


The authors would like to thank the ADEME (Agence de l'ENvironnement et de la Maitrise de l'Energie) for financial support through Ph.D grant for Mélissa Landart. We thank Flavien Delarbre (Engineering program - Polytech Lyon) for preliminary experiments in free-solvent dimerization and Catherine Goux Henry (Teacher-researcher - Université Lyon 1 Claude Bernard) for SEC analysis.

\section{ABBREVIATIONS}

PE, pentaerythritol; DPE, dipentaerythritol, TPE, tripentaerythritol; DMSO, dimethyl sulfoxide; CPME, cyclopentyl methyl ether; DMI, 1,3-dimethyl-2-imidazolidinone; NMP, N-methyl-2pyrrolidone; TMP, trimethylolpropane; di-TMP, ditrimethylolpropane; TME, trimethylolethane; di-TME, di-trimethylolethane; GLY, glycerol; di-GLY, di-glycerol; PTSA, para-toluenesulfonic acid

\section{REFERENCES}

(1) Hu, J.; Zhang, L.; Ma, H. Hexa-Functionality Urethane Acrylate Based on Dipentaerythritol and Preparation Method and Application of Hexa-Functionality Urethane Acrylate. CN105860026 (A), August 17, 2016.

(2) Gu, J.; Zhang, G.; Dong, S.; Zhang, Q.; Kong, J. Study on Preparation and Fire-Retardant Mechanism Analysis of Intumescent Flame-Retardant Coatings. Surface and Coatings Technology 2007, 201, 7835-7841.

(3) Yokoshima, M.; Nawata, K.; Ohkubo, T.; Hattori, H. (Meth) Acrylate Esters of Dipentaerythritol Caprolactone Condensates. US4540809, September 10, 1985.

(4) Van Den Haak Hendrik, J. W.; Macliver, R. J.; Di Lullo, C. A.; Cameron, C.; Soldavini, L.; Ganesh, B. Pigment Concentrate. WO2008037678, April 3, 2008.

(5) Xu, peng. Building Material Brick with High Fire Resistance. CN107663920, February 6, 2018.

(6) Bengtsson, H.-A.; Nyman, L.-H. Process for Producing Monopentaerythritol of High Purity and Monopentaerythritol Produced by the Process. WO2007089197 (A1), August 9, 2007.

(7) Wawzonek, S.; Rees, D. A. Formation of Ethers in the Preparation of Pentaerythritol. Journal of the American Chemical Society 1948, 70, 2433-2435.

(8) Kanbara, Y.; Idemoto, T.; Ono, K.; Kubota, C. Production of Dipentaerythritol. JPH03261736 (A), November 21, 1991. 
(9) Yamamoto, T.; Katsuura, A. Production of Dipentaerythritol. JPH04208242 (A), July 29, 1992.

(10) Kambara, Y.; Idemoto, T.; Ono, Y.; Tona, C. Process for Producing Dipentaerythritol. US5254749 (A), October 19, 1993.

(11) Wada, N.; Shoji, T.; Yamamoto, K.; Nakajima, T. Method for Producing Polyhydric Alcohol Ethers. JP2004175710 (A), June 24, 2004.

(12) Li, L.; Kamiya, Y.; Okuhara, T. Catalytic Dehydration of Pentaerythritol to Dipentaerythritol over Heteropoly Compounds. Applied Catalysis A: General 2003, 253, 29-32.

(13) Kanbara, Y.; Idemoto, T.; Ono, K.; Kubota, T. Production of Dipentaerythritol. JPH04145040 (A), May 19, 1992.

(14) Watabe, Y.; Hazama, S.; Ono, K.; Kanbara, Y.; Koga, E. Production of Dipentaerythritol. JPH0616585 (A), January 25, 1994.

(15) Yoshida, T.; Jinno, T. Method for Producing Dipentaerythritol. JP2002105013 (A), April 10, 2002.

(16) Malec, R. E. Synthetic Lubricants. US3673226 (A), June 27, 1972.

(17) Martin, A.; Checinski, M. P.; Richter, M. Tuning of Diglycerol Yield and Isomer Distribution in Oligomerization of Glycerol Supported by DFT-Calculations. Catalysis Communications 2012, 25, 130-135.

(18) Sayoud, N.; De Oliveira Vigier, K.; Cucu, T.; De Meulenaer, B.; Fan, Z.; Lai, J.; Clacens, J.-M.; Liebens, A.; Jérôme, F. Homogeneously-Acid Catalyzed Oligomerization of Glycerol. Green Chem. 2015, 17, 4307-4314.

(19) Karam, A.; Sayoud, N.; De Oliveira Vigier, K.; Lai, J.; Liebens, A.; Oldani, C.; Jérôme, F. Heterogeneously-Acid Catalyzed Oligomerization of Glycerol over Recyclable Superacid Aquivion ${ }^{\circledR}$ PFSA. Journal of Molecular Catalysis A: Chemical 2016, 422, 84-88.

(20) Dubois, P.; Coulembier, O.; Raquez, J.-M. Handbook of Ring-Opening Polymerization; 2009.

(21) Bull, J. A.; Croft, R. A.; Davis, O. A.; Doran, R.; Morgan, K. F. Oxetanes: Recent Advances in Synthesis, Reactivity, and Medicinal Chemistry. Chem. Rev. 2016, 116, $12150-12233$.

(22) Christ, E.-M.; Hobernik, D.; Bros, M.; Wagner, M.; Frey, H. Cationic Copolymerization of 3,3-Bis(Hydroxymethyl)Oxetane and Glycidol: Biocompatible Hyperbranched Polyether Polyols with High Content of Primary Hydroxyl Groups. Biomacromolecules 2015, 16, 3297-3307. 